\title{
Positive Returns and Equilibrium: Simultaneous Feedback between Public Opinion and Social Policy
}

\author{
Nate Breznau*, Mannheim Centre for European Social Research (MZES) \\ breznau.nate@gmail.com
}

\begin{abstract}
This paper pushes forward political research from across disciplines seeking to understand the linkages between public opinion and social policy in democracies. It considers the thermostatic and the increasing returns perspectives as pointing toward a potentially stable set of effects running between opinion and policy. Both theoretical perspectives argue that opinion and policy are reciprocally causal, feeding back on one another. This is a general argument found in opinion-policy literatures. However, much empirical research claims to model "feedback" effects when actually using separate unidirectional models of opinion and policy. Only a small body of research addresses opinion-policy endogeneity directly. In this paper I consider an opinion-policy system with simultaneous feedback and without lags. I argue that there is a theoretical equilibrium in the relationship of opinion and policy underlying the otherwise cyclical processes that link them. Given that available cross-national data are cross-sectional and provide limited degrees of freedom, an ideal theoretical model must be somewhat constrained in order to arrive at empirically meaningful results. In this challenging and exploratory undertaking I hope to open up the possibility of a general system of effects between public opinion and social policy and how to model them in future research. I focus on social welfare policy as it is highly salient to public interests and a costly area of government budgets, making it an area of contentious policymaking. Social policy is also a major part of the thermostatic model of opinion and policy, which was recently extended to the cross-national comparative context (Wlezien \& Soroka, 2012) providing a critical predecessor to this paper because identification of equilibrium between public opinion and social policy in any given society is greatly enhanced through comparison with other societies. This counterfactual approach helps to identify opinionpolicy patterns that may not change much within societies, but can be seen as taking on discrete trajectories between societies.
\end{abstract}

Keywords: Public Opinion, Social Policy, Welfare States, Simultaneous Feedback

*This paper is forthcoming at Policy Studies Journal: https://doi.org/10.1111/psj.12171. I am grateful to those active on the SEMNET listserve and the anonymous reviewers. Many thanks also go to feedback from Alexi Gugshvili, Liza Steele, Anthony Sealey, Nadine Schöneck-Voss, Christoph Burkhardt, Judith Offerhaus, Christopher Wlezien, Bernhard Ebbinghaus, Tobias Wolbring, Sergi Vidal, J. Timo Weishaupt and Ralf Götze at various stages in this research. 
This paper pushes forward political research from across disciplines seeking to understand the linkages between public opinion and social policy in democracies. It considers the thermostatic and the increasing returns perspectives as pointing toward a potentially stable set of effects running between opinion and policy. Both theoretical perspectives argue that opinion and policy are reciprocally causal, feeding back on one another. This is a general argument found in opinion-policy literatures (Campbell 2012). However, much empirical research claims to model 'feedback' effects when actually using separate unidirectional models of opinion and policy. Only a small body of research addresses opinion-policy endogeneity directly. In this paper I consider an opinion-policy system with simultaneous feedback and without lags. I argue that there is a theoretical equilibrium in the relationship of opinion and policy underlying the otherwise cyclical processes that link them. Given that available cross-national data are cross-sectional and provide limited degrees of freedom, an ideal theoretical model must be somewhat constrained in order to arrive at empirically meaningful results. This challenging and exploratory undertaking I hope to open up the possibility of a general system of effects between public opinion and social policy and how to model them in future research.

I focus on social welfare policy, i.e., features of the modern welfare state such as pensions, health care, labor market and family policies, as it offers direct transfers of goods or services from the government to members of the public, making it a highly salient area for public opinion. In addition it is a costly area for governments, making it a subject of contentious policymaking. Social policy is also a major part of the thermostatic model of opinion and policy, which is presently a state of the art approach to modeling feedback effects (Soroka and Wlezien 2010). Originally it was based on empirical research on single country cases but recently Wlezien and Soroka (2012) applied the model to the cross-national comparative context. The latter is a critical predecessor to this paper because identification of equilibrium between public opinion and social policy in any given society is greatly enhanced through comparison with other societies. This counterfactual approach helps to identify opinion-policy patterns that may not change much within societies, but can be seen as taking on discrete trajectories between societies.

\section{Public Opinion And Social Policy: What Relationship in Democracies?}

The thermostatic model of public preferences by Wlezien (1995) and its later theoretical developments discussing feedback running between opinion and policy (Soroka and Wlezien 2010), follows in a tradition of research suggesting that the public are responsive to spending in the form of proposed or actual changes (Durr 1993; Wlezien and Soroka 2007), and policymakers and policymaking processes are responsive to public demands both real and imagined (Converse 1987; Hill and Hinton-Andersson 1995; Page and Shapiro 1983), both of which should move opinion and policy toward congruence. In the responsive democratic polity, the political denizen ${ }^{1}$ has allegiance to the system as well as opportunities to influence system outcomes, for example through enfranchisement, minority veto, and regular rotation of offices (Lipset 1960). Policies should move toward the preferences of the median or

\footnotetext{
${ }^{1}$ A reference to Lipset's (gendered) conception of the 'political man'.
} 
average voter (Downs 1957). If a policy moves away from the median, there will be more members of the public dissatisfied with it leading to an eventual change in the policy back toward the median preference, in this way the public acts as a thermostat partially regulating policy spending (Wlezien 1995). The same applies when spending moves toward the median-voter because public preferences to increase policy will be allayed and thus reduced. In both cases the public moves negatively against the direction of a spending change. However, this negative response is a product of public opinion relative to policy and policy changes, and does not reflect a change in opinion as to what the absolute or ideal level of overall policy should be. As I will show in the next section, formal equations are available to express the thermostatic model.

Not necessarily incompatible with the thermostatic model, the increasing returns model of Paul Pierson $(1998,2000)$ suggests that legally defined policy entitlements generate positive public opinion. The materials and services given to individuals via welfare state policies lead to public reliance on the state and public opinion in support of these returns from the state. The public tend to enjoy whatever level of benefits they receive and tend to demand more over time, leading political actors to want to offer more as a way to gain power. The nature of returns and public support are linked to particular historical 'happenstance' configurations of social policies and the institutions that sprang up around them; some examples being Bismarck's worker protections to ally them with the state against socialism in Germany (Lidtke 1966), the initially racially coded and controversial 'Old-Age Retirement, Survivors and Disability Insurance' in the U.S. (Skocpol 1988) or care for Civil War veterans also in the U.S. (Skocpol 1992), or subsidies for agricultural sales in Sweden linking to large cross-class coalitions (Weir and Skocpol 1985). Recipients, workers in agencies of government, and individuals along economies of scale associated with providing state goods and services have a material self-interest in maintaining and expanding given policies. Therefore, they tend to form or support special interest groups, and this mobilizes public opinion through informal social interaction, media and party politics.

The increasing returns model is an institutionalist account of opinion-policy where each reinforces the other over periods longer than annual cycles. Borrowed from economics, the idea of increasing returns explains political behaviors as structured by incentives and especially disincentives generated by historical institutional trajectories (e.g. North 1990). Once political institutions are in place it is inefficient to change them and more rational to adjust individual or group political strategies to work within them (Pierson 1993). The values, ceremonies, norms (informal rules), laws (formal rules), myths and habits that are built into social policy institutions play key roles in shaping political behaviors and collective problem solving. These embedded features come to define what constitutes 'rational' policymaking behaviors or responses to collective problems, including attitude formation and heuristic shortcuts (Homans 1974; Jepperson 1991; Ostrom 2011; Weber 1946, 229). The process of institutionalization means that what was before comes in time to be seen as what ought to be (Hall and Taylor 1996; Meyer and Rowan 1977; Thelen 1999), an argument found in the institutional analysis and development framework and rational choice theories (see review in Nowlin 2011). The results are national systems that expand along discrete institutional trajectories; what policy scholars might call 'worlds of welfare' (Esping-Andersen 1985), and institutional theorists 
might call 'institutional isomorphism' (DiMaggio and Powell 1983). In short, increasing returns means path dependency (Ebbinghaus 2005a; Lijphart 1999).

In the increasing returns perspective policy moves positively in response to public opinion similarly to the thermostatic model, because policymakers and parties pick up on public shifts in 'mood' and then make corrections to policies (Stimson, Mackuen, and Erikson 1995). Policymakers tend to alter their policymaking behaviors to reflect what they perceive to be public preferences (a product of historical experiences and expectations), and these perceptions reflect actual public preferences - with some room for error due to asymmetric information (Butler and Nickerson 2011; Jones and Baumgartner 2004). The thermostatic model points toward cyclical processes usually considered as happening over budgetary or election cycles. In this perspective there is an opinion-policy relationship where policy outcomes are constantly pulled toward opinion leading to a system of equilibrium, other policy shocks notwithstanding; similar to a punctuated equilibrium linkage where the impact of opinion on policy is stronger closer to more intense policymaking periods, such as elections or budgetary deadlines (Jones and Baumgartner 2012). Thus, the thermostatic model likely feeds into increasing returns trajectories by helping the system stay on the path. Unlike the thermostatic model, the increasing returns model has no formal equations. Quantitative models have been used only rarely to test for increasing returns, probably because measuring institutional embeddedness is a great challenge. The bulk of the argument is rational-theoretical or based on historical comparative, qualitative and descriptive data (Pierson 1993, 1994, 2000).

Although usually applied to expansions, the mechanism of increasing returns could also explain declining returns $^{2}$. Globalization, economic stagnation and ageing demographics may reduce social benefits without policymakers taking any actions of policy cuts (Hacker 2004; Pierson 2002). Also, when policymakers do retrench social policy the public may not notice, as these cuts are purposely hidden or too complicated to understand by the public (Korpi and Palme 2003; Pierson 1996; Schumacher, Vis, and van Kersbergen 2013; Thelen 2014). Regardless of how it happens, social policy retrenchment has taken on many forms since the 1980s in most rich democratic welfare states (Starke 2006). As a result the public should expect less from the state and expect to compete more in a private marketplace for social insurance and welfare. As these new rules of the game become embedded, individuals who must compete more in private may become less supportive of state provided social provisions. Thus, it is plausible that opinion and policy mutually decrease each other, which means they retain a positive relationship but move simultaneously in a negative direction. I adopt the label positive returns to apply Pierson's theoretical mechanisms to both directions.

The feedback perspectives of the thermostatic and positive returns thesis suggest a systems perspective (e.g. Durkheim 1964; Easton 1965; Luhmann 1982). From this perspective the system follows a trajectory determined by its current state and the environment, e.g., disasters, media frenzies, crime, and any other external stimuli to opinionpolicy. In the system, policymaking has implications for the entire system (Anderies and Janssen 2013), and public

\footnotetext{
${ }^{2}$ I opt for "declining returns" here to avoid confusion because "decreasing returns" typically refers to some kind of diminishing marginal utility in economics.
} 
opinion is both outcome of and input into policymaking, and therefore the entire system as well (Mettler and Soss 2004). However, without equilibrium there is no system, and all effects between opinion and policy are eventspecific. For example, others have shown how a shock to either opinion or policy leads to changing, reverberating and decaying effects over years around the event (e.g. Jennings 2009). However, here I consider that shocks are constantly impacting opinion-policy systems and at the core there is a stable relationship that exists to absorb all of the shocks. This is an argument for a general theory of opinion-policy applicable across events and contextspecificities.

\section{Simultaneous Feedback: From Theory to Model Specification}

The thermostatic model may be expressed as two equations (Wlezien and Soroka 2012, 1409-1410):

$$
\begin{aligned}
& R_{t}=a+\beta_{1} P_{t}+\beta_{3} W_{t}+e_{t} \\
& \Delta P_{t}=\rho+y_{1} R_{t-1}+y_{2} G_{t-1}+u_{t}
\end{aligned}
$$

Feedback takes place via Equation 1 as public responsiveness and Equation 2 as policy representation. In Equation 1 , relative public preferences $R_{t}$ for a policy are equal to the slope $\beta_{1}$ (i.e., effect) of policy output $P_{t}$ (they measure it as spending) plus the slope $\beta_{3}$ of absolute public preferences $W_{t}$ (unobserved but estimated by proxy); plus intercept $a$ and error $e_{t}$. Equation 1 assumes that relative preferences are observed in a survey and represent the difference between existing levels of spending and absolute preferences for spending. In Equation 2, a change in $P_{t}$ equals the slope $y_{1}$ of relative public preferences in the previous year $R_{t-1}$ plus the slope $y_{2}$ of partisan control of government in the previous year $G_{t-1}$ (relative rates of left and right parties); and intercept $\rho$ and error $u_{t}$.

The slope of public responsiveness $\left(\beta_{1}\right)$ is always negative because the public want spending $\left(P_{t}\right)$ to move toward their more stable absolute preferences $\left(W_{t}\right)$ (see also Roosma, van Oorschot, and Gelissen 2014 and Steele 2015 for alternative approaches to relative and absolute preferences). Meanwhile, the slope of policy representation $\left(y_{1}\right)$ is positive because it follows what the public wants. Taken together, spending (and spending changes) will move public opinion to react negatively immediately and then in the next year, policy will change positively in response.

These two equations suggest a feedback loop because any change in spending or opinion triggers subsequent changes in the other. Of course these effects trigger subsequent effects, and the feedback process swings like a pendulum until the effects caused by any single change in the system return to zero. This process is estimated by Soroka and Wlezien (2010) to take about 10 years. But given that opinion and policy are regularly changing in response to economic, demographic, and media persuasion factors, the pendulum of effects is in fact perpetually in motion. Reconsidering the positive returns model here, absolute preferences may change over many years as policy provisions change. Thus, opinion may feedback on itself through policy and the system can be at equilibrium while moving in a certain direction, with or without shocks.

Although Soroka and Wlezien estimate feedback, they estimate Equation 1 and 2 separately and then combine the results post-hoc. This generates a potential unobserved endogeneity problem because the results of each 
equation is dependent on the other. No scholar to date explicitly employed endogeneity correcting models in the case of social welfare policy and specific policy preferences, but there is blossoming analogous research using various lagged variable models to deal with autocorrelation (i.e., endogeneity), most often a form of vector autoregression (VAR) (Freeman, Williams, and Lin 1989). These models account for different short-term and long-term effects of opinion and policy on each other. For example, Jennings (2009) considers a thermostatic model of border control and asylum policy with public opinion finding that as preferences for less immigrants and asylum seekers increase, the applications and case numbers processed decreases. Jennings also demonstrates that shocks to the system in terms of changes in asylum applications have effects that persist at a decaying rate across years, similar to the predictions about moving toward equilibrium in the theoretical model of Wlezien and Soroka. Others have looked at left-right subjective placement and the content of policy speeches, and the linkages between media messages and public opinion using similar methods (Habel 2012; Hakhverdian 2012; Lee 2014). The lagged variables models are powerful tools to assess opinion-policy, but their greatest strength lies in identifying opinion-policy feedback at specific moments before, during and after policy change.

Perhaps there is a perpetual relationship of opinion and policy, not specific to any moment. This would mean underlying thermostatic feedback and increasing returns together captures a stable set of effects between opinion and policy characterized by equilibrium. If present, these effects would weather exogenous shocks to the opinion-policy system. It is difficult if not impossible to capture all shocks to opinion and social policy stemming from culture, constitutional structure, corporatism, religion or other normative forces (Breznau 2015; Hall and Lamont 2013; Huber, Ragin, and Stephens 1993; Larsen 2008). Most poignantly, media diffusion and persuasion is ever jolting public and policymaker responsiveness alike (Miller and Stokes 1963; Mullinix 2011). Such specific mechanisms are very difficult to quantify and when omitted from an empirical model they potentially confound estimation of the causal paths between opinion and policy (Knight and Winship 2013; Pearl 2009). I argue that estimating simultaneous effects despite these potential omitted confounders is acceptable because each context has fixed-effects that define the unique features of socio-political relations in each society but should be randomly distributed across societies, leaving findings representative of the total effects of opinion or policy on each other. The question is whether opinion and policy operate as a system at equilibrium despite context-specific effects.

To estimated simultaneous feedback I first theorize in more detail about equilibrium (section 2.1), then I use theoretical steps to specify a structural model from the Wlezien and Soroka equations into a nonrecursive system (2.2), and finally I discuss instrumental variables necessary to identify the effects (2.3). All of these stages require interplay of theory and methods as models cannot be estimated without certain components and these components cannot be identified without theoretical arguments.

\subsection{Equilibrium}

The reciprocal effects of opinion and policy on each other must be theoretically causal forces (or total effects of various causal forces) that exist at the same time and occur perpetually. Extreme shocks or inefficiencies caused 
by corruption, war, or transitioning away from a planned economy characterize disequilibrium. Thus, I focus on rich democracies which did not face extreme political shocks after WWII. There are small disruptions such as election cycles, media frenzies, new special interest groups, and economic booms and busts causing opinion-policy shifts (Papadakis 1992). But the overall political institutions and rule of law persist without spiraling into revolution or chaos.

As argued in both the thermostatic and positive returns literatures, policymakers are constantly gauging public opinion and attempting to predict how the public will respond to their actions (Miller and Stokes 1963; Stimson, Mackuen, and Erikson 1995). This means that public opinion has an effect on policymaking that is constant existing in the minds of policymakers. Even if there are shocks to public opinion, policymakers still expect the public to react to policymaking practices in certain, predictable ways and adjust their behaviors accordingly. Policy also has a stable effect on opinion from an institutional perspective. The resources distributed by policies in cash and in-kind are slow to change, thus the public develop normative expectations that guide attitudes and behaviors. The returns from the state shape public opinion to favor the institutionalized welfare status quo (Pierson 2000) and the public tend toward uncertainty avoidance making them likely to oppose changes whose outcomes seem unclear (Bartels 1986). As social policies are exceedingly complex, the public are unlikely to understand what policy changes mean, and be averse to any changes (Pierson 1996).

Wlezien and Soroka state that opinion and policy are constantly moving toward equilibrium. This movement takes place in cycles where effects are feeding back between opinion and policy. Soroka and Wlezien $(2010,179)$ estimate that a disturbance takes about a decade to return to equilibrium. I assume that disturbances to the opinionpolicy relationship are perpetually taking place. Thus, every potential observation window includes feedback effects that are coming to a close, in the middle, or just started. Thus, from a longer-term perspective the system is perpetually moving, but moving in a steady way; for example public opinion over the course of a year (as opposed to daily, weekly, and etc.) smooths out erratic fluctuations, leaving a more consistent pattern. With policy, periods less than a year yield small changes if any, because of annual budget-making and the slow process of policy-change (Tepe and Vanhuysse 2010). There are budgetary changes within years and these are relevant for policymakers and the public, but are small in comparison to policy viewed over many years. Except for largescale legal policy changes, the replacement rates for things like pensions and unemployment rarely change, and when they do they sometimes take a long time to implement. Even recent liberalizations and retrenchments of social policy after the 1980s have small impacts on current pensioners for example because cuts fall more onto future cohorts (Thelen 2014), leading to what Pierson $(1993,2002)$ refers to as a 'sticky' institutional process.

\subsection{Model Specification}

Figure 1 represents the Wlezien and Soroka thermostatic model drawn from Equations 1 and 2, expressed as a path diagram (Wright 1934). I deconstruct this path diagram with the process of equilibrium in mind.

\section{Figure 1. The Thermostatic Model as a Path Diagram}




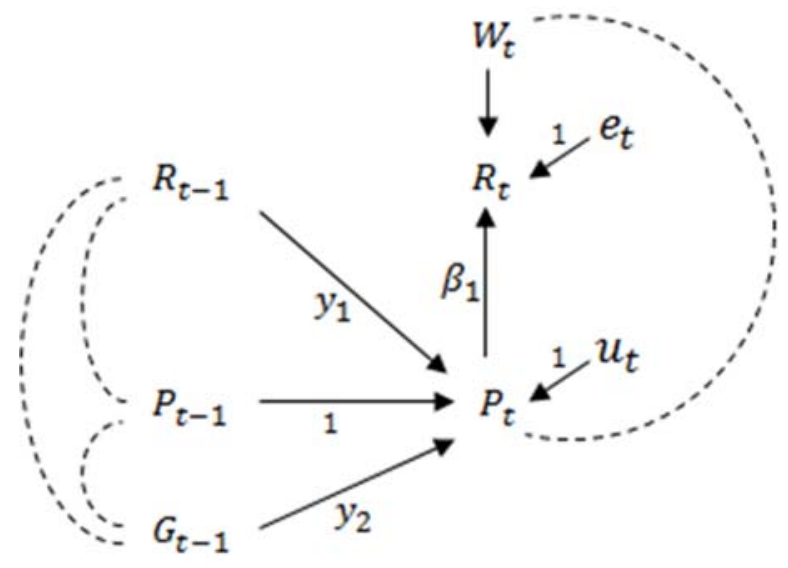

In Figure 1, solid arrows are effects and labeled to match Equations 1 and 2, while dotted lines are correlations. I assume mean-centered variables (no mean structure). The error terms are some disturbance from the predicted values linked by an effect size of one. The lagged measure of policy $P_{t-1}$ is not in Equation 2, but is part of the dependent variable $\Delta P_{t}\left(=P_{t}-P_{t-1}\right)$ as it appears after adding $P_{t-1}$ to both sides of Equation $2^{3}$.

There are sources of bias in Figure 1. The first is that previous policy shapes present public opinion. Relative preferences change based on how policy presently differs, or not, from before. Thus, $P_{t-1}$ should have an arrow toward $R_{t}$. Also, $P_{t-1}$ likely shapes $W_{t}$ because previous policy has an institutional or normative impact on what individuals come to expect and prefer. Second, partisan control of government $G_{t-1}$ is likely correlated with $W_{t}$, because a lagged measure of $W_{t}$ at the time that seats were distributed in the last election should have shaped public voting behaviors at that time. As absolute preferences are stable over short periods of time, any previous version of $W$ will then be highly correlated with its later-self. Therefore, any measure of $G$ is not independent of $R_{t}$ because $W$ is a general cause of $R$. This argues for a current measure of $G$ as opposed to a lagged measure.

A second bias is the impact of current opinion on current policy. For example, public opinion may motivate executive orders that cause immediate spending or even policy changes, it may influence current judicial decisions, and might proxy the level of need for welfare among the public which in turn predicts the level of spending that year. The former cases are more exceptional, but the latter conjecture suggests that factors such as unemployment, labor market vitality, public health, old age quality of life, and other social welfare needs in a society cause opinion change and simultaneously cause policy (spending) change. Need is a strong predictor of support for social welfare policies, and of course need also reflects spending due to take-up of social benefits (Andreß and Heien 2001; Gelissen 2000; Meltzer and Richard 1981). As all sources of need cannot be measured an empirical space exists for opinion to have a measurable impact on policy, as indirect through needs. Moreover, as the experience of needing welfare can be a profound life course shaping event it should shape absolute preferences which directly determine relative preferences

\footnotetext{
${ }^{3}$ This is a purposeful oversimplification of change-scores to move forward with model construction (Allison 1990)
} 
$R_{t}$. So, causal mechanisms aside, taking up a policy leads to a change in attitudes and a change in spending on that policy, and theoretically leads to a measurable effect of opinion on policy in the same year.

\section{Figure 2. Potential Sources of Bias}

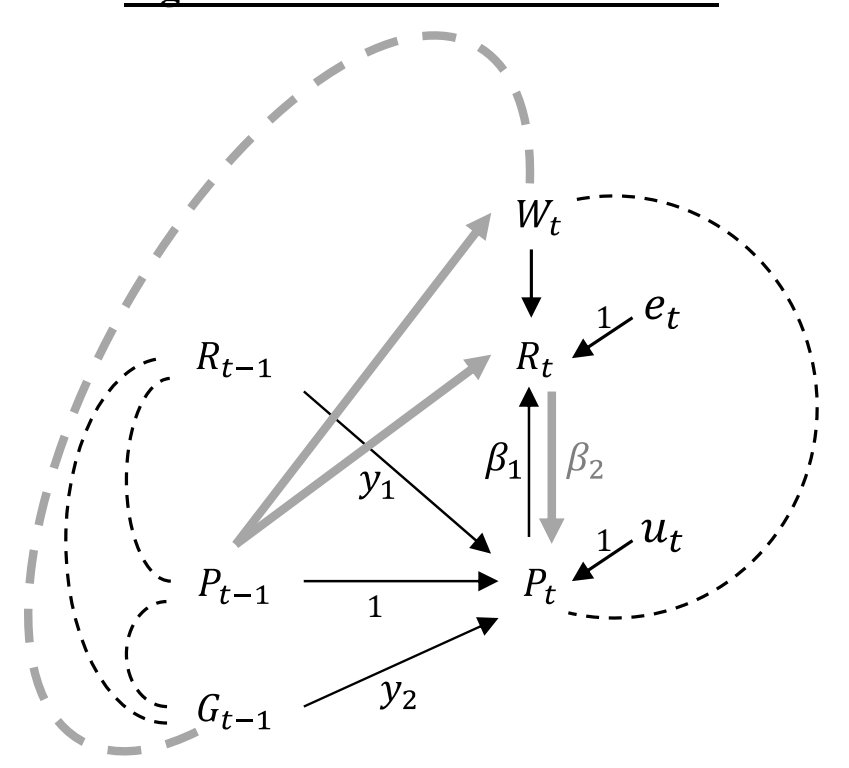

In Figure 2, thicker grey lines represent biasing paths that should be present in a theoretical model of opinion and policy. Although biasing paths can be controlled for with independent variables, the feedback loop now present between $R_{t}$ and $P_{t}$ creates endogeneity that undermines estimates in independent Equations 1 and 2.

The models in Figures 1 and 2 cannot be estimated using comparative survey data because of the lagged opinion effect $R_{t-1}$. Opinion is not measured yearly in any comparative survey covering a large number of countries. Instead, opinion is measured in intervals of 2-6 years depending on the survey and country. However, I question the utility of using only one year lagged variables. Recent research suggests that the impact of opinion and policy on each other changes depending on the length of a lag (Jennings 2009). Therefore, I would potentially need a decade of lags, measured yearly to capture an adequate array of effects. Moreover, as I, and Wlezien and Soroka argue: the relationship between opinion and policy perpetually moves toward equilibrium, and effects are constantly starting, progressing and coming to a close. This constant movement of opinion and policy toward each other suggests that regardless of when they are observed they should be found in perpetual motion on a shared path. This renders the lagged variables unnecessary if not biasing for the purpose of estimating simultaneous effects at equilibrium. Assuming this movement is similar across time and space is the key proposition of the general simultaneous feedback theory I advance here, as argued in section 2.1 on equilibrium. Relying on this theory of equilibrium I drop lagged effects.

In Equation 1, a measure of policy is necessary to estimate $R$ rendering endogeneity into the estimate (as shown by the feedback loop in Figure 2). Practically, $W$ is not observed in questions about the government providing more or less on a given policy. Thus, the question arises how to estimate $W$ and $R$. There is a solution in questions 
regarding the role of government. Such questions found in several cross-national surveys probe the degree of agreement that respondents express regarding the government's role to provide various social policies. Implicitly these questions contain both $W$ and $R$ as they are correlates of both the preferred role (i.e., absolute ideal-level of provisions) and the perceived performance (i.e., relative preference for provisions) (Roosma, van Oorschot, and Gelissen 2014). Therefore I estimate $O$, which is simply a measure of both $W$ and $R$ simultaneously. These changes plus the addition of $X$ to represent a set of all potential independent variables that cause both opinion and policy other than partisan control of government are reflected in my final feedback model in Figure 3.

\section{Figure 3. Path Diagram of Simultaneous Opinion-Policy Feedback}

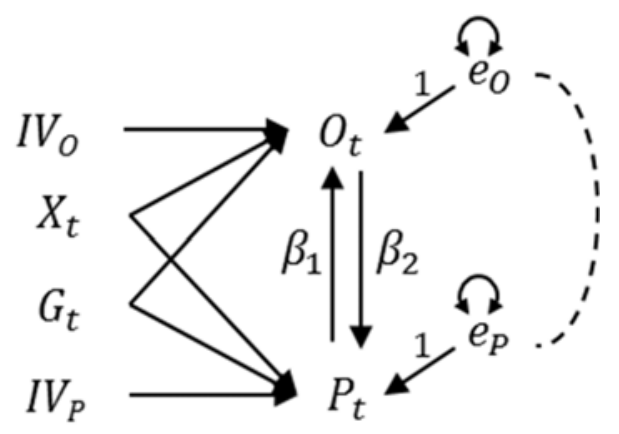

For identification this model requires that: (a) there are as many model observations as unknown statistical parameters (i.e., the counting rule that model degrees of freedom must be $\geq 0$ ), and (b) at least one more case exists in the observed data than free parameters (Kline 2011). I am interested only in effects and not mean structures, thus for (a): Figure $3^{4}$, has 11 parameters or model moments ( 2 variances and 1 covariance of $e_{O}$ and $e_{P}, 4$ covariances of $O$ and 4 covariances $P$ each with $I V_{O}, I V_{P}, G_{t}, X$, and 1 covariance between $O$ and $P$. In Figure 3 there are 11 effects (4 arrows pointing at $O_{t}$ and 4 pointing at $P_{t}$, and residuals with 2 variances and 1 covariance between them). In the most basic version of the model there are 11 parameters -11 effects $=0$ degrees of freedom leaving a just identified model. However, I also consider an alternative model where the intercepts of latent $O$ and $P$ are constrained to zero. Models with and without the means constrained to zero are identical in that they capture deviations from a center point and not any mean structure. The latter model has the benefit of 13 parameters and thus 2 degrees of freedom useful for model comparison (Paxton, Hipp, and Marquat-Pyatt 2011,6). The addition of more $X$ variables does not change the model degrees of freedom; however, it increases the number of free parameters.

For (b): The number of free parameters in the model determines the minimum number of cases needed in the data. Free parameters are those which are freely estimated, not observed. Thus, with 11 free parameters at least 12 cases are needed in the data to achieve over-identification. While sampling theory suggests 10 observations in the data per free parameter or variable are necessary to have trustworthy effects when working with population data

\footnotetext{
${ }^{4}$ i.e., treated as exogenous in a structural equation model - also the default estimation procedure in MPlus software.
} 
(Pedhazur 1997), country-level data are arguably not a sample from a population, for sure not a random sample (Ebbinghaus 2005b). Although this leads to an imperfect statistical reality, estimations are still possible and when coupled with counterfactual or historical analysis, researchers routinely rely on less than 10 cases per parameter, if not using the minimum in deterministic studies (Bollen, Entwisle, and Alderson 1993). I do not claim to have determined all causes of opinion and policy, that is why I have the residual correlation $e_{O}, e_{P}$ in Figure 3 , this leaves the somewhat ambiguous goal of getting as many cases as possible per parameter.

Public opinion measure. The International Social Survey Program (ISSP) is the only comparative public opinion data covering a globally broad sample of rich democratic countries ${ }^{5}$; this was likely the motivation for Wlezien and Soroka's (2012) cross-national work. The ISSP Role of the Government and Religion modules each have two questions on social policy related to income redistribution and employment ${ }^{6}$. This makes usage of 70 data points in 19 countries possible. Having only one $X$ variable in Figure 3 requires 12 or more cases in the data to have at least 1 or more degrees of freedom and each additional $X$ variable adds 2 free parameters; thus I set the maximum at $3 X$ variables in addition to $G$ which yields 15 free parameters leaving only (19-15=) 4 degrees of freedom for maximum likelihood identification. I would call this a bare minimum.

Policy measures. The theoretical arguments and empirical evidence underlying the thermostatic model and the positive returns model diverge with respect to policy. The thermostatic model is focused on spending and budgeting while the returns model is about replacement rates and the generosity of other welfare entitlements - also known as decommodification. These are highly correlated. However, budgets are also flexible and spending can change without an explicit policy change. Therefore, I seek to test models of both spending and legal entitlements. I measure spending from the OECD social expenditures variable ("SOCX"). This measure is the amount of public social welfare spending expressed as a percentage of GDP (OECD 2012) ${ }^{7}$. Mostly it comes from pensions and health care and then to a lesser degree (un)employment, family policies, housing and a few others. Decommodification is from the dataset compiled by Lyle Scruggs (2004) and measures the replacement rates and the generosity of welfare policies. Decommodification measures more precisely how social policy impacts individual welfare; however, the variable only extends to 2002 and is not available for two countries thus reducing the sample size. Both spending and decommodification fluctuate slightly from year-to-year within-countries but vary widely between-countries making them suited for observing comparative longer-term trends without the need for longitudinal analyses.

\footnotetext{
${ }^{5}$ The European Social Survey could provide a source but this would be a restricted sample.

${ }^{6}$ The ISSP 'Role of Government' ('85,'90,'96,'06) and 'Religion' ('91,'98) modules provide a 2-item scale which is part of a larger 6-item scale asking about the welfare state more generally with pensions and health care (Cronbach's alphas are 0.62 and 0.71 respectively), unfortunately the 6-items are fielded in far less surveys (43 as opposed to 70 cases).

${ }^{7}$ This is the standard variable in cross-nationally comparative social welfare policy research (Brooks and Manza 2007; GreenPedersen 2004; Kenworthy 1999; Pampel and Williamson 1988), despite its known problems (Castles 2009). Like Wlezien and Soroka (2012) I use this measure for its utility and comparability across societies.
} 


\subsection{Instrumental Variables}

When there are two endogenous feedback outcomes, a statistical model is nonrecursive and cannot be identified (Kline 2011, 134). There is a vast literature on this subject, with much technical detail (Bollen 1989, 2012; Duncan, Haller, and Portes 1968; Kline 2011, 2013; Pedhazur 1997, 292). One critical rule is that at least one instrumental variable must be in the model for each endogenous (dependent) variable. These instruments must have a causal effect on either opinion or policy while having no causal effect on the other, i.e., an effect of zero. Reviewing opinion-policy research reveals two options for instrumental variables ${ }^{8}$.

Veto points is an instrument for social policy. The constitutional structure and political institutions of a country create a setting which enables or constrains social policymaking. More competitive veto points means more opportunities for blocking legislation, what Lijphart (1999) refers to as the "federal-unitary dimension" of national political systems (see also Crepaz and Moser 2004). Thus the electoral and judicial systems of a country have a direct impact on social policy based on how the policies are formed into law (Däubler 2008). In rich democracies, the institutions of veto have not changed since before $1985^{9}$. Thus, veto points represent stable political institutions that should not impact public attitudes which are otherwise changing in response to current political events. One attractive argument in favor of using veto points is that it has a successful track-record in previous research (Matsusaka 2005; Poterba 1995), in particular Gabel and Scheve (2007) argue that electoral institutions (part of how veto points are measured) are exogenous to public opinion.

Female labor force participation (female LFP) should be an instrument for public opinion. Employment leads individuals to be less supportive of social welfare, all else equal (Gelissen 2000), and presumably more female LFP means more women employed which leads to a reduction in overall support of social welfare among women for reasons of material security. Employed women or women who have been or expect to be employed (as is true of all persons) are less likely to need public or partner-based provisions for their welfare because they can privately provide their own, and they may be less willing to use their earned income to fund welfare via taxation; these are classic arguments of material self-interest (Andreß and Heien 2001). As male labor force participation varies far less than female LFP across rich democracies, this instrument captures something unique in public opinion. However, there is a clear association with the rise of female employment and social policy. It appears that the expanding role of women working in the public sector coincided, if not interacted with, the political development of the welfare state and thus shaped policy spending (Huber and Stephens 2000). This causal argument could rule out female LFP as a valid instrument; however, this argument applies to early, post-war welfare state expansions prior to the rise of comparative public opinion surveys in the 1980s.

\footnotetext{
${ }^{8}$ There are alternatives such as military spending, tax systems, and post-materialist development, but these are difficult to measurement or may have more serious endogeneity problems. Although not exhaustive, the two selected are derived from 4 years of dissertational and postdoc research.

${ }_{9}$ At least for the countries I analyze in this paper. Two small exceptions are New Zealand (Vowles 1995), and Italy in 1994 (Lijphart 1999).
} 
Sometime during the 1980s, female LFP in the United States and Canada for example caught up with that of Scandinavian social democracies and today women work at similarly high rates. In the US and Canada this is presumably a result of a highly commodified labor market where working is necessary for survival (Esping-Andersen 1990). Incidentally these two countries spend nearly the least on social welfare of all rich democracies, while Sweden and the Netherlands for example have similarly high female LFP rates but spend some of the most on social welfare policy. Thus, nearly opposite types of welfare states in terms of policy have similarly high female LFP. Moreover, the familial tradition of the Mediterranean countries leads to relatively low female LFP, but these countries have moderate spending levels, much higher than the U.S. but lower than Northern Europe. Thus, female LFP does not appear to cause social policy in a comparative context since the 1980s. Moreover, in many countries female LFP continues to rise while spending decreases.

\subsection{Nil Policy Feedback Hypotheses}

When policies are initiated or reformed, a variety of interests meet to see them through to their street-level implementations. This process may lead to what Patashnik and Zelizer (2013) refer to as "incomplete displacement" and "inadequate state capacity" to bring about major and stable policy changes at the level of individual recipients. This harks to Piersons' 'sticky' conceptualization of the new politics of welfare where institutionalized policymaking gets in the way of efforts at lasting policy change (see also Soss and Schram 2007). Without effectual material changes resulting from policy change, long term public opinion should not change as a response. At the same time, these varieties of interests that make and implement policy change may collectively ignore public opinion as each potentially represents a different segment of the public, or represents no public interest. Therefore, it is possible that increasing returns only applied to the historical rise of welfare states policies, and these mature and institutionalized polices no longer bring about sustainable opinion change (Raven et al. 2011), or only lead to opinion change in subsets of the population (Bendz 2015), or that opinion does not cause policy change and is instead just manufactured by private interests (Habermas 1989). Therefore, it is possible that there is no system-stable effect of policy on opinion and especially opinion on policy. Given the decisive effect of policy, it may drive the entire system and constrain or enable its own future via policymakers despite public opinion (see also K. J. Morgan and Campbell 2011).

\section{VARIABLES AND MODELS}

Individual predictors of opinion. Much previous research identifies socioeconomic and demographic determinants of public opinion (attitudes, preferences, and etc.). For example, women on average are more supportive of government provided social services such as pensions, health care, general (re)distribution, and (un)employment support across countries (Bean and Papadakis 1998; M. D. R. Evans, Kelley, and Peoples 2010; Hasenfeld and Rafferty 1989; Taylor-Gooby 2001). Also, older persons tend to be more supportive, although age, period and cohort 
effects may explain inconsistencies (Jæger 2006; Svallfors 1997). These findings point toward material interests as a key factor in public opinion: aged persons more likely to support pensions, unemployed more supportive of unemployment benefits, and more materially secure persons are generally less supportive (Blekesaune and Quadagno 2003; Breznau and Eger 2016; Breznau 2010; Eger 2010).

Weaker economies encourage public opinion to be more supportive of social policy also out of need, thus lower levels of GDP per capita and higher rates of unemployment should predict lower support for social policy (Blekesaune 2007; Gërxhani and Koster 2012). Finally, as argued by Soroka and Wlezien, the percentage of the total seats held by right parties (variable $G$ ) as opposed to left or other parties should reflect less support of social welfare policy (and spending), but also lead to less provision of welfare through their policymaking agendas (Huber, Ragin, and Stephens 1993; Jensen 2011). Thus, partisan control links both to opinion and policy.

Predictors of policy. In addition to partisan control of government, the distribution of welfare needs in a given society is the largest predictor of social spending. Where there are more sick, unemployed and especially pensioners there are higher levels of social spending. As pensioners are also at a point in the life course that has higher medical costs, the percentage of the population over age 64 is a critical predictor variable (Pampel and Williamson 1988). Brooks and Manza (2007) provide a lengthy discussion of factors impacting social spending. In addition to the above, they also discuss the theoretical impact of GDP per capita (see also Wilensky 1975), and growth over time.

Dependent variables for public opinion, spending and decommodification were already described in section 2.2 .

Table 1 summarizes all variable definitions (correlations in online appendix ${ }^{10}$ ).

\footnotetext{
${ }^{10} \mathrm{https}: / /$ sites.google.com/site/nbreznau/publications
} 
Table 1. Variable Names and Definitions

\begin{tabular}{|c|c|c|c|}
\hline Name & Type & Measurement $^{\mathrm{a}}$ & Source \\
\hline $\begin{array}{l}\text { Public } \\
\text { Opinion }\end{array}$ & $\begin{array}{l}\text { Endogenous } \\
\text { Dependent Variable }\end{array}$ & $\begin{array}{l}\text { Two-item scale from respondents level of } \\
\text { agrrement with the responsibility of } \\
\text { government to provide jobs and reduce } \\
\text { income differences. }\end{array}$ & $\begin{array}{l}\text { ISSP Role of Government } \\
\text { (I,II,III,\&IV) and Religion } \\
\text { (I\&II) modules }\end{array}$ \\
\hline $\begin{array}{l}\text { Social } \\
\text { Spending }\end{array}$ & $\begin{array}{l}\text { Endogenous } \\
\text { dependent variable } \\
\text { measuring Social } \\
\text { Policy }\end{array}$ & $\begin{array}{l}\text { The amount of spending on social policy } \\
\text { provisions, mostly pensions, employment, } \\
\text { unemployment, and health care expressed } \\
\text { as a percentage of GDP in the same year. }\end{array}$ & $\begin{array}{l}\text { OECD (2012); also known } \\
\text { as "SOCX" }\end{array}$ \\
\hline $\begin{array}{l}\text { Decomm- } \\
\text { odification }\end{array}$ & $\begin{array}{l}\text { Endogenous } \\
\text { dependent variable } \\
\text { measuring Social } \\
\text { Policy }\end{array}$ & $\begin{array}{l}\text { An aggregate score of generosity and } \\
\text { replacement rate levels. Intended to } \\
\text { measure how much or how little an } \\
\text { individual must rely on the labor market or } \\
\text { private funds for prosperity. }\end{array}$ & Scruggs (2004) \\
\hline Aged & Independent variable & Percent of the population over age 64 . & OECD Social Indicators Data \\
\hline Right & Independent variable & $\begin{array}{l}\text { Percent of national government seats held } \\
\text { by right parties. }\end{array}$ & $\begin{array}{l}\text { Svennson et al. (2012); } \\
\text { Quality of Government Data }\end{array}$ \\
\hline Unemp. & Independent variable & Percent of the labor force that is unemploy & OECD Social Indicators Data \\
\hline GDP & Independent variable & Gross Domestic Product at PPP. & OECD Social Indicators Data \\
\hline Female LFP & $\begin{array}{l}\text { Instrument for } \\
\text { Public Opinion }\end{array}$ & $\begin{array}{l}\text { Percent of the total female population in } \\
\text { the labor force. }\end{array}$ & OECD Social Indicators Data \\
\hline Veto Points & $\begin{array}{l}\text { Instrument for both } \\
\text { Social Policy } \\
\text { variables }\end{array}$ & $\begin{array}{l}\text { A scale of institutional measures for the } \\
\text { amount of chances a policy has to be } \\
\text { vetoed. Based on the work of Lijphart } \\
\text { (1999). }\end{array}$ & $\begin{array}{l}\text { Svennson et al. (2012); } \\
\text { Quality of Government Data }\end{array}$ \\
\hline
\end{tabular}

${ }^{a}$ All variables are measured simultaneously at the current year of the endogenous variables.

Models. Table 2 summarizes all models. The letters “A\&B" denote models with social spending as the policy measure, and "D\&C" for decommodification. I start with only one independent variable. I tried right party control, but many of the models had identification problems, so instead I use aged first. For each configuration of variables, I specify three models. The first allows $\beta_{1}$ and $\beta_{2}$ to be freely estimated. The second follows Wlezien and Soroka's (2012) thermostatic model and constrains $\beta_{1}$ to be negative and $\beta_{2}$ to be positive similar to their estimates. The third assigns equal, moderate sized effects for $\beta_{1}$ and $\beta_{2}$ to represent positive returns. 
Table 2. Specifications for Simultaneous Feedback Models

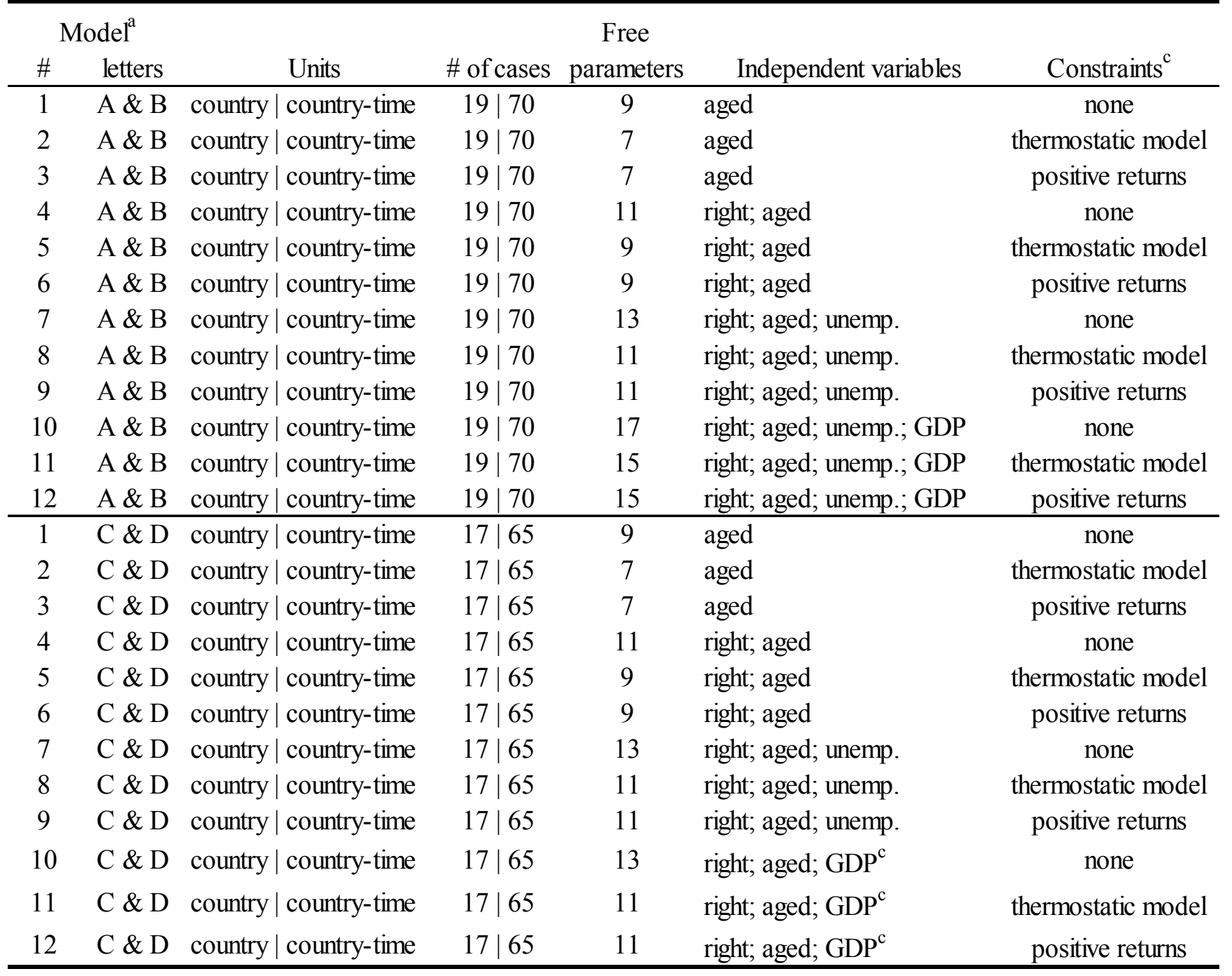

\footnotetext{
${ }^{a}$ All models have female labor force participation as instrumental variable for opinion and veto points as instrument for policy. For each numbered model, letters A \& B have spending and C \& D have decommodification as the policy measure. See Figure 4.

${ }^{\mathrm{b}}$ Thermostatic model has fixed metric effect sizes based on Wlezien and Soroka's (2012) results, and positive returns model has moderate and similar sized positive effects for both $\beta_{1}$ and $\beta_{2}$.

${ }^{\mathrm{c}}$ Models 10, 11 and $12 \mathrm{C} \& \mathrm{D}$ have unemployment omitted because it is highly endogenous with GDP; also, a second set of models were estimated with the mean of both dependent variables set at zero generating 2 les parameters and two more model degrees of freedom - see Tables 5, 6 and 7 in the online appendix, https://sites.goggle.com/site/nbreznau/publications.
}

\section{Results}

Table 3 reports the main results from 12 specifications of Models A-D. For each set of specifications I placed the preferred model in bold, and Figure 4 diagrams these preferred models. 
Table 3. Simultaneous Opinion-Policy Feedback Models ${ }^{a}$

\begin{tabular}{|c|c|c|c|c|c|c|c|c|c|c|c|c|c|c|c|c|c|c|c|c|c|c|c|}
\hline \multirow{3}{*}{$\begin{array}{c}\text { Model } \\
\#\end{array}$} & \multicolumn{3}{|c|}{ Feedback effects } & \multicolumn{11}{|c|}{ Fit statistics } & \multicolumn{9}{|c|}{ Independent variable effects } \\
\hline & \multicolumn{2}{|c|}{ Std.-YX coeff. } & \multirow{2}{*}{$\begin{array}{c}\text { Resid. } \\
\left(\mathrm{e}_{\mathrm{o}}, \mathrm{e}\right)\end{array}$} & \multicolumn{4}{|c|}{ chi-square $^{b}$} & \multirow[b]{2}{*}{ RMSEA } & \multirow[b]{2}{*}{ LL } & \multirow[b]{2}{*}{ CFI } & \multirow[b]{2}{*}{ AIC } & \multirow[b]{2}{*}{ BIC } & & & $\beta_{\mathrm{AC}}$ & ef & & & Pu & & & $P$ & $\beta_{\mathrm{FLP}} \beta_{\text {Veto }}$ \\
\hline & $\beta_{1}$ & $\beta_{2}$ & & value $d$ & & $H_{0}$ & $\mathrm{H}_{1}$ & & & & & & PO & SP & PO & SP & PO & SP & PO & SP & PO & SP & PO \\
\hline $1 \mathrm{~A}$ & 0.78 & -0.02 & -0.61 & 0.0 & 0 & - & -- & 0.00 & -69 & 1.00 & 156 & 164 & 0.36 & 0.30 & 0.04 & 0.58 & & & & & & & $-0.56-0.26$ \\
\hline $2 \mathrm{~A}$ & $-0.05^{*}$ & 30 * & .06 & .7 & 2 & * & 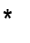 & 14 & -70 & 0.96 & 154 & 161 & 0.50 & 0.36 & 50 & & & & & & & & $-0.51-0.23$ \\
\hline $3 \mathrm{~A}$ & $0.15^{*}$ & $15^{*}$ & 16 & 1.4 & 2 & * & & 0.00 & -70 & 1.00 & 153 & 160 & 0.54 & 0.38 & 40 & & & & & & & & $51-027$ \\
\hline $4 \mathrm{~A}$ & 0.80 & 09 & .80 & 0.0 & 0 & - & -- & 00 & -64 & 1.00 & 149 & 160 & 0.29 & 0.47 & .03 & 0.51 & -0.0 & & & & & & $-0.57-0.26$ \\
\hline $5 A$ & $.06^{*}$ & $24^{*}$ & .24 & 3.6 & 2 & * & * & 0.21 & -66 & 0.94 & 149 & 158 & 0.38 & 0.57 & 50 & 0.40 & & & & & & & $-0.56-0.32$ \\
\hline $6 \mathrm{~A}$ & $0.15^{*}$ & $15 *$ & .41 & 1.8 & 2 & * & * & 0.00 & -65 & 1.00 & 147 & 156 & 0.62 & 0.48 & 39 & 0.47 & -1 & & & & & & $0.57-0.34$ \\
\hline $7 A$ & 0.91 & 16 & .87 & 0.0 & 0 . & - & -- & 0.00 & -63 & 1.00 & 151 & 164 & 0.20 & 0.46 & -0.03 & 0.48 & & & .12 & & & & $0.65-0.26$ \\
\hline $8 \mathrm{~A}$ & $.05^{*}$ & $30^{*}$ & .33 & 4.6 & 2 & * & * & 0.26 & -65 & 0.90 & 152 & 62 & 0.64 & 0.43 & 0.49 & 1 & & & .12 & & & & $0.64-0.35$ \\
\hline $9 \mathrm{~A}$ & $0.15^{*}$ & $15^{*}$ & .45 & 2.8 & 2 & * & * & 0.14 & -64 & 0.97 & 150 & 61 & 0.64 & 0.48 & 0.38 & 48 & -( & & 4 & & & & $0.68-0.37$ \\
\hline $10 \mathrm{~A}$ & 0.56 & 0.28 & -0.80 & 0.0 & 0 . & - & -- & 0.00 & -61 & 1.00 & 151 & 166 & 0.58 & 0.47 & 0.17 & 0.42 & & & 26 & & 0 & & $-0.54-0.29$ \\
\hline $11 \mathrm{~A}$ & $-0.05^{*}$ & $0.31^{*}$ & -0.23 & 2.6 & 2 & * & * & 0.13 & -62 & 0.98 & 150 & 162 & 0.74 & 0.46 & 0.49 & 0.41 & & & 26 & & 37 & & -0.5 \\
\hline $12 \mathrm{~A}$ & $0.15^{\star}$ & $0.15^{*}$ & -0.39 & 1.4 & 2 & * & * & 0.00 & -61 & 1.00 & 149 & 161 & 0.73 & 0.49 & 0.39 & 0.48 & -0.4 & & .27 & & -0.37 & & $-0.57-0.36$ \\
\hline $1 \mathrm{~B}$ & $0.84^{\dagger}$ & 0.05 & -0.6 & 0.0 & 0 . & - & - & 0.00 & -268 & 1.00 & 559 & 84 & 0.17 & 0.34 & -0.05 & 0.53 & & & & & & & $-0.53-0.22$ \\
\hline $2 B$ & $-0.05^{*}$ & $31^{*}$ & -0.08 & 7.2 & 2 & & & 0.19 & -272 & 0.92 & 562 & 32 & 0.41 & 0.34 & .43 & & & & & & & & $-0.51-0.21$ \\
\hline 3B & $0.15^{*}$ & $15^{*}$ & -0.15 & 3.6 & 2 & * & * & 0.11 & -270 & 0.98 & 558 & 79 & 0.45 & 0.35 & 32 & 0.48 & & & & & & & -0.24 \\
\hline 4B & 0.81 & -0.13 & -0.50 & 0.0 & 0 & - & - & 0.00 & -261 & 1.00 & 549 & 578 & 0.16 & 0.39 & 0.05 & 0.51 & -0.0 & & & & & & -0.22 \\
\hline $5 B$ & $-0.05^{*}$ & $31^{*}$ & -0.16 & 7.9 & 2 & & & 0.21 & -265 & 0.93 & 553 & 578 & 0.48 & 0.37 & 0.44 & 0.42 & -0.26 & & & & & & -0.24 \\
\hline $6 B$ & $0.15^{*}$ & $0.15^{*}$ & -0.24 & 4.2 & 2 & * & * & 0.13 & -264 & 0.97 & 549 & 574 & 0.50 & 0.40 & 33 & 0.49 & -0.22 & & & & & & 0.26 \\
\hline $7 \mathrm{~B}$ & $1.03^{\dagger}$ & .00 & -0.74 & 0.0 & 0 . & - & -- & 0.00 & -264 & 1.00 & 551 & 584 & 0.00 & 0.40 & -0.15 & 0.56 & -0.05 & & -0.20 & & & & $0.68-0.23$ \\
\hline $8 \mathrm{~B}$ & $-0.05^{*}$ & $31^{*}$ & -0.16 & 10.1 & 2 & & & 0.24 & -265 & 0.90 & 557 & 586 & 0.48 & 0.37 & 0.44 & 0.42 & -0.27 & & .03 & & & & $0.57-0.24$ \\
\hline $9 B$ & $0.15^{\star}$ & $0.15^{\star}$ & -0.23 & 58 & 2 & * & * & 0.17 & -263 & 0.95 & 552 & 582 & 0.50 & 0.40 & 33 & 0.49 & & & .0 & & & & -0.2 \\
\hline $10 \mathrm{~B}$ & $0.71^{\dagger}$ & & -0.6 & 0.0 & 0 & - & - & 0.00 & -258 & 1.00 & 550 & 588 & 0.35 & 0.41 & 0.05 & 0.51 & & & .26 & & 2 & & -0. \\
\hline $11 \mathrm{~B}$ & $-0.05^{*}$ & $31^{*}$ & -0.1 & 5.4 & 2 & * & * & 0.16 & -261 & 0.96 & 551 & 85 & 0.53 & 0.39 & 0.47 & 0.40 & & & .13 & & .28 & & -0.4 \\
\hline $12 \mathrm{~B}$ & $0.15^{*}$ & & -0.2 & 2.7 & 2 & * & * & & -259 & 0.99 & 548 & 32 & 0.56 & & 36 & 0.47 & & & & & 8 & & -0.4 \\
\hline $1 \mathrm{C}$ & 0.50 & -0.12 & 0.1 & & 0 & - & & & -57 & 1.00 & 132 & 40 & 0.78 & 0.24 & 23 & & & & & & & & $-0.65-0.41$ \\
\hline $2 \mathrm{C}$ & $0.06^{*}$ & $27^{*}$ & & & 2 & * & & & -59 & 0.94 & 132 & & & & & & & & & & & & $0.66-0$. \\
\hline 30 & & & & & 2 & * & & & -58 & 1.00 & & & & & & & & & & & & & 0. \\
\hline $4 C$ & & & & & 0 & - & & & -52 & 1.00 & 131 & 12 & 0.78 & & & & & & & & & & -0.4 \\
\hline $5 \mathrm{C}$ & & $7^{*}$ & & & 2 & * & & & -54 & 0.94 & 131 & 10 & 0.62 & & & & & & & & & & 0 \\
\hline $6 C$ & & & & & 2 & * & & & -53 & 1.00 & 129 & & 0.71 & & & & & & & & & & $.66-0$. \\
\hline 70 & & & & & 0 & - & & & -49 & 1.00 & 124 & & 0.78 & & & & & & & & & & $0.69-0.43$ \\
\hline 80 & & & & & 2 & 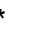 & & & -5 & & 125 & & & & & & & & & & & & $3-0.39$ \\
\hline 9 & & & 0.2 & & 2 & * & 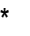 & & -51 & & 124 & & 0.70 & & & & & & & & & & -0.43 \\
\hline & & & & & 0 & - & & & -52 & 0 & 1 & & & & & & & & & & 0.02 & & \\
\hline & & & & & 2 & * & & & -5 & 0.95 & 129 & & & & & & & & & & 01 & & \\
\hline c & & & & & 2 & 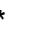 & & & -53 & 1.00 & 128 & & 0 & 0. & 9 & 0.40 & -0.23 & & & & 0.00 & & $-0.65-0.42$ \\
\hline $1 \mathrm{~L}$ & 0.4 & & & 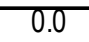 & 0 & - & & & -240 & 1.00 & 2 & & & & & & & & & & & & 35 \\
\hline 2 & & & & & 2 & & & 0.23 & -2 & 0.92 & 507 & 7 & & & & & & & & & & & \\
\hline 0 & & & & & 2 & * & & & -242 & 0. & 502 & 2 & & & & & & & & & & & \\
\hline A & & & & & 0 & & & . & -232 & 1.00 & 492 & 520 & 0.66 & & & & & & & & & & -0.6 \\
\hline 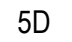 & & & & & 2 & & & 0.22 & -237 & 0. & 496 & 520 & 0.48 & & & & & & & & & & 1 \\
\hline 0 & & & & & 2 & * & & & -234 & 0.99 & 491 & 4 & & & & & & & & & & & 0 \\
\hline 7[ & & & & & 0 & & & & -231 & 1.00 & 493 & 525 & 0.67 & & & & & & & & & & \\
\hline 8[ & & & & & 2 & & & & -234 & 0.96 & 494 & 523 & 0.47 & & & & & & & & & & \\
\hline 9[ & & & & & 2 & * & & & -232 & 1.00 & 491 & 519 & 0.58 & & & & & & & & & & \\
\hline 10 & & & & & 0 & & & 0.00 & -231 & 1.00 & 494 & 526 & 0.67 & & & & & & & & 06 & & \\
\hline 11 & -0.0 & 2 & & 0.0 & 2 & & & 0.17 & -235 & 0.96 & 495 & 523 & 0.46 & & & & & & & & 0.10 & & $-0.66-0.31$ \\
\hline תח & 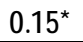 & $15^{*}$ & 33 & .1 & 2 & 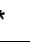 & & 0.02 & -233 & 0.99 & 492 & 520 & 0.57 & 0.48 & .31 & 0.35 & -0 & & & & 0.07 & 0.1 & $-0.65-0.34$ \\
\hline
\end{tabular}

${ }^{a} \beta 1$ is effect of policy on opinion and $\beta 2$ is opinion on policy. "PO" is short for public opinion and "SP" for social policy. Significance values * $p<.05, \uparrow p<.10$ only reported for feedback effects. See Table 2 for more details.

$b$ "df' is model degrees of freedom; $\mathrm{H}_{0}$ tests exact-fit hypothesis, ${ }^{*} \mathrm{p}>.05 ; \mathrm{H}_{1}$ is equal-fit hypothesis that the current model is better fiting than the larger model in each group with identical independent variables taken from meanstructure models in Appendix Table 6, * $p>.01$ (see Kline 2010, Ch. 8 "Hypothesis Testing").

CIn an equal-fit test between meanstructure model of $7 \mathrm{C}$ and $12 \mathrm{C}, 12 \mathrm{C}$ is preferable, see online appendix Table 6 at https://sites.google.com/site/nbreznau/publications 


\section{Figure 4. Results of Simultaneous Feedback Models of Public Opinion and Social Policy}

Model A. Social spending, country units

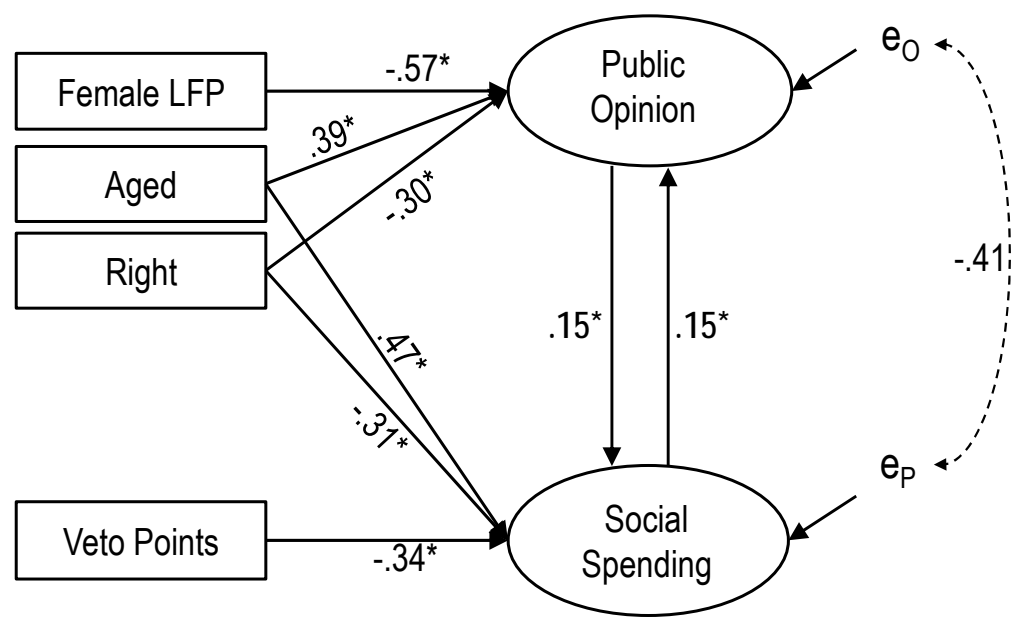

Model B. Social spending, country-time units

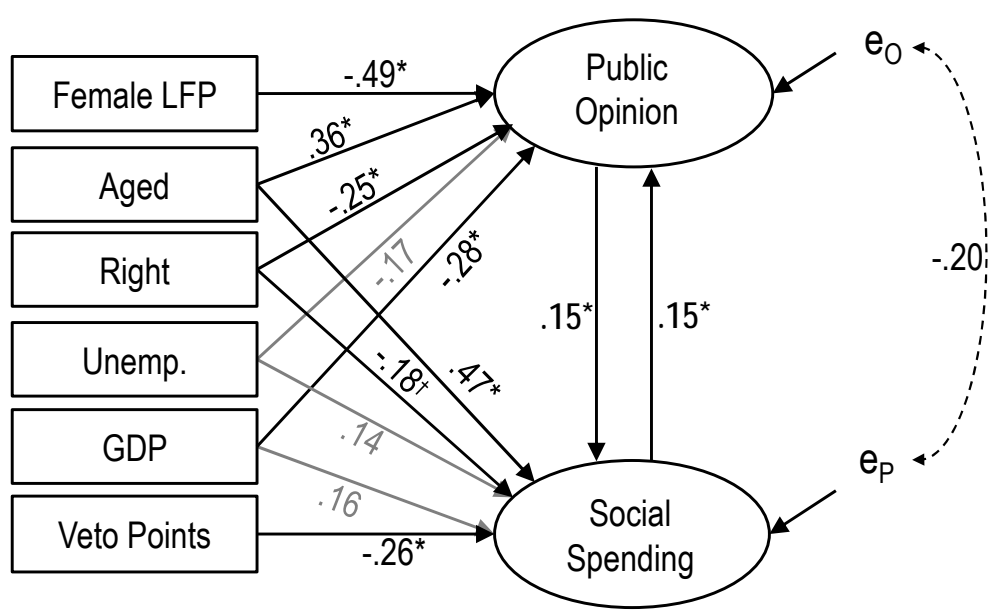

Model C. Decommodification, country units

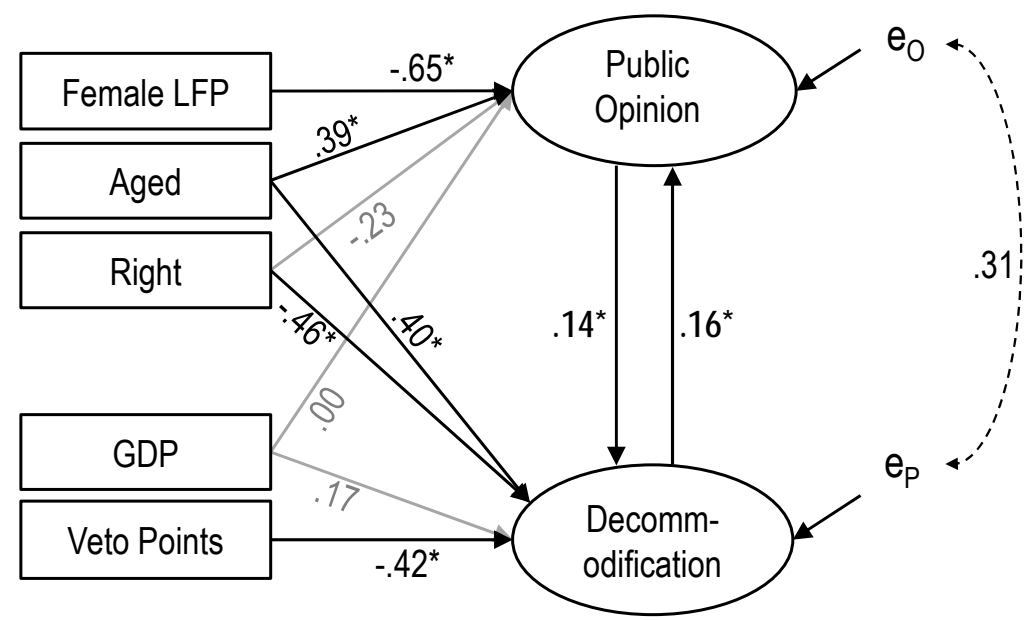

Model D. Decommodification, country-time units

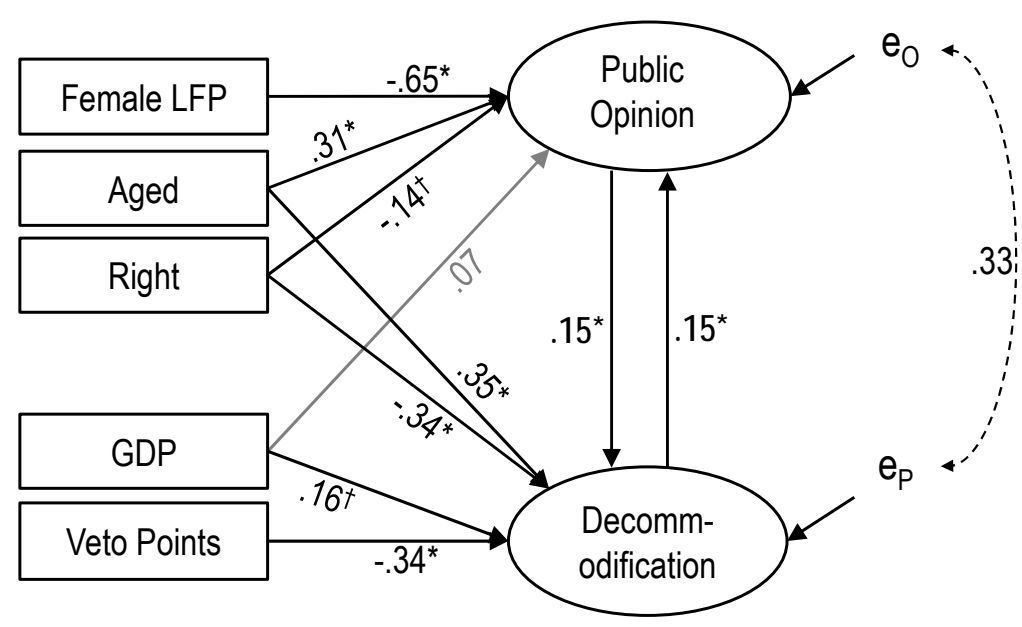

Coefficients are $\mathrm{XY}$-standardized and $\mathrm{p}<.05\left(^{*}\right)$ and $\mathrm{p}<.10\left({ }^{\dagger}\right)$. 
In Figure 4, grey represents non-significant paths ${ }^{11}$ and numbers are standardized coefficients plus a residual correlation between $e_{O}$ and $e_{P}$. All four preferred models support the positive returns perspective in both policy spending and decommodification. Preferred Model 6A $(\mathrm{N}=19)$ has a moderate sized positive effect of policy on opinion $\beta_{1}=0.15$ and a similar effect of opinion on policy $\beta_{2}=0.15$, and this model fits better than the thermostatic and freely estimated models, and better than models with more independent variables. Model $12 \mathbf{B}(\mathrm{N}=70)$ has similar effects as $6 \mathrm{~A}$ with $\beta_{1}=0.15$ and $\beta_{2}=0.15$. In Model $12 \mathbf{C}$ and $12 \mathrm{D}, \beta_{1}=0.16$ and 0.15 , and $\beta_{2}=0.14$ and 0.15 respectively.

To select preferred models in Table 3, I looked at a variety of fit statistics. The first criterion is a chi-square exact fit test that the difference between the observed and implied moment matrices is zero reported in column $\mathrm{H}_{0}$, where a star indicates that at $\mathrm{p}>.05$ the model is consistent with the data. . As the freely estimated $\beta_{1}$ and $\beta_{2}$ models are just-identified, they do not have chi-square tests and I must rely on LL, AIC and BIC. Then I used an equal fit test that the nested constrained model was better fitting than the larger model with freely estimated $\beta_{1}$ and $\beta_{2}$, for each set of models employing the same independent variables. I borrow this test from the mean structure models in Table 6 where a star indicates that at $\mathrm{p}>.01$ the larger model does not fit better as shown in column $\mathrm{H}_{1}$ in Table 3 . Next I looked across the remaining fit statistics and aimed to find the best combination. Many fit statistics are within just a few points of each other making it plausible that the preferred model is not obviously better than another. This suggests that in the case of spending, the thermostatic model may fit equally well as the positive returns model; however, in all cases the chi-square and fit statistics pointed in the direction of the positive returns model. The case of decommodification has similar evidence. Here evidence points toward the positive returns model as favorable in C Models, but the freely estimated model could fit better in the D Models, except for 12D the preferred model whose equal-fit test rejects the freely estimated model.

Table 5 in the online appendix ${ }^{11}$ provides a number of alternative models as sensitivity checks: including a known scale measurement error for public opinion, unemployment in Models 10-12 C\&D, constrained nil effects for either policy on opinion $\left(\beta_{1}=0\right)$ or opinion on policy $\left(\beta_{2}=0\right)$, and two equally plausible alternatives to Models $11 \& 12$. These models do not alter the main findings that the positive returns model, estimated in a variety of ways, is superior. The nil effect models provide an interesting alternative, in that when freely estimated, the effect of policy on opinion could be zero in one out of four models (Model X1A). The effect of opinion on policy could be zero in all four models (X2A-D). The possibility of a zero effect is problematic. The coefficient that represents a potentially zero effect of policy on opinion in X1A is 0.78 . This is a massive sized standardized effect. The only reason it includes zero is because it has very braod confidence bands, i.e., this is not evidence that it is zero. A similar story can be told about opinion on policy. Although at between 0.11-0.24 (Models X2A-D) the effects are closer to zero, they still have very

\footnotetext{
${ }^{11}$ Note that the grey paths are significant at $\mathrm{p}<.2$ and have substantial mathematically sized effects. I do not wish to engage in a debate about p-hacking, but alert the reader to the fact that they matter in size.
} 
broad confidence intervals. Moreover, these models do not fit better than the preferred models, leading to evidence against the nil hypothesis

As an exploratory exercise I find an argument for what ideal sizes of effects might be in both the thermostatic and positive returns theoretical perspectives (from Models $11 \& 12 / \mathrm{C} \& \mathrm{D}$ ) by tweaking the size of $\beta_{1}$ and $\beta_{2}$ until I achieve the best possible model fit (all indices considered). In Model 11BT (Table 5), I show that reducing the size of the negative policy responsiveness to about half of what Wlezien and Soroka recommend (down to $\beta_{1}=-0.03$ ), in addition to reducing the size of the opinion representation effect slightly (down to $\beta_{2}=0.13$ ) produces a more optimal fit for both spending and decommodification measures. In the positive returns model - which fits even better - I find that having a very large impact of spending $\left(\beta_{1}=0.33\right)$ and an even larger effect of decommodification $\left(\beta_{1}=0.45\right)$ on opinion is optimal when combined with a much smaller impact of opinion on spending $\left(\beta_{1}=0.11\right)$ and on decommodification $\left(\beta_{1}=0.09\right)$. Figure 5 positive returns models (lower two models) present what I believe to be ideal empirical approximations of the systems perspective theory given these data. I report the ideal thermostatic models out of interest, but the positive returns models fit better here. 
Figure 5. Opinion-Policy Feedback Model Results after Optimization

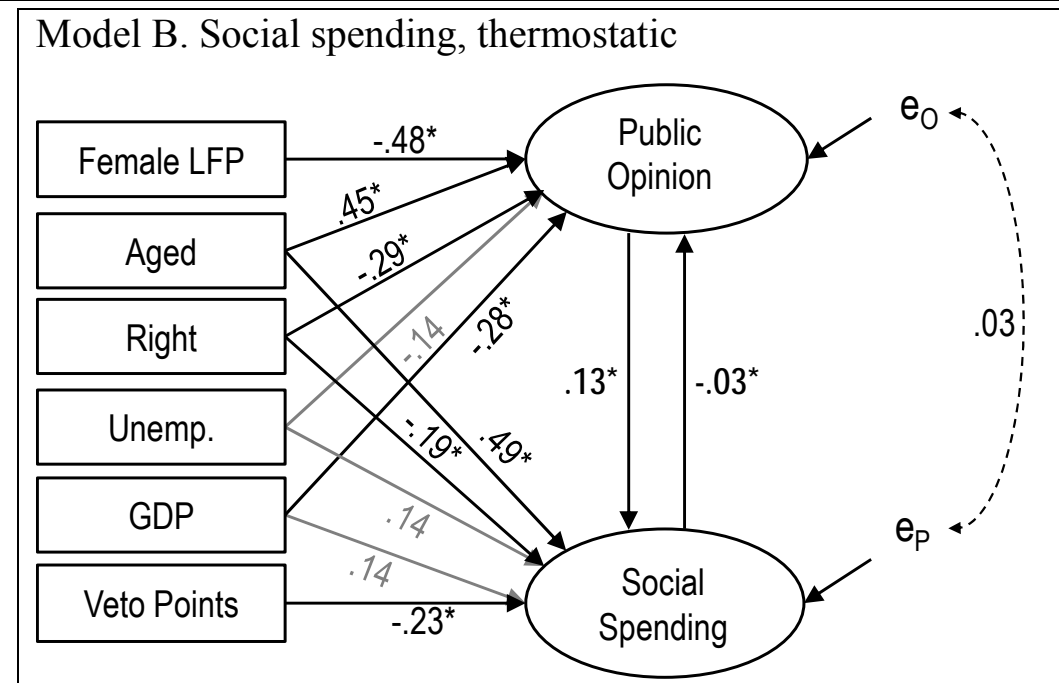

Model B. Social spending, positive returns

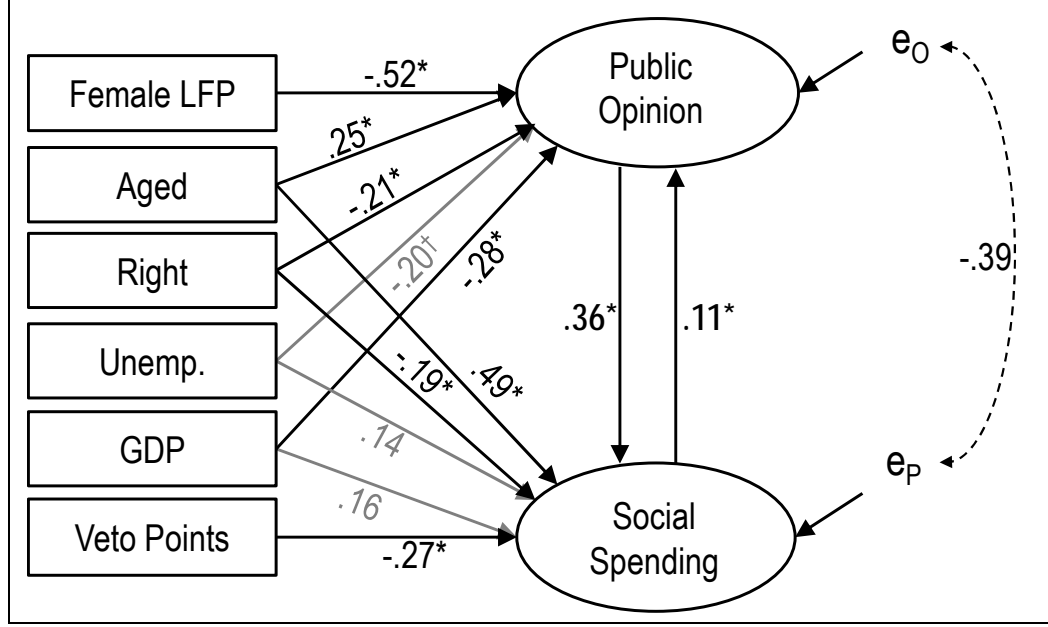

Model D. Decommodification, thermostatic

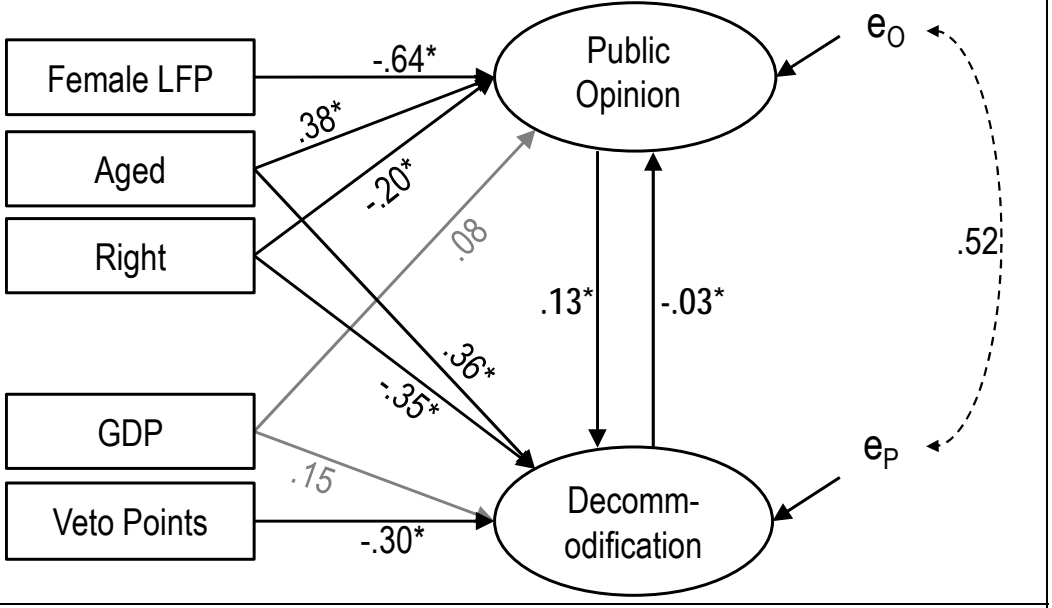

Model D. Decommodification, positive returns

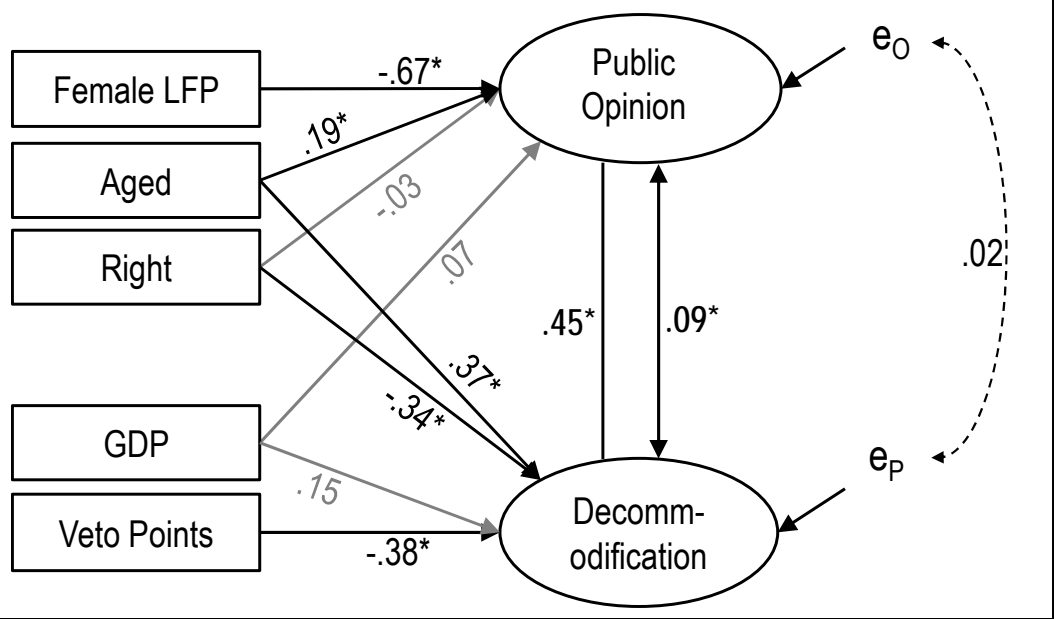

Coefficients are $\mathrm{XY}$-standardized and $\mathrm{p}<.05\left(^{*}\right)$ and $\mathrm{p}<.10\left(^{\dagger}\right)$. 


\section{Discussions}

\subsection{Implication of Findings}

The thermostatic model has some empirical support, but the evidence favors the positive returns model. But these are not competing theories. They both represent how inputs arrive into a system of equilibrium. If negative reactions constitute relative preferences, and relative preferences are driven by absolute preferences, then it is the absolute preferences that are more important to the long-term policy linkages as modeled here ('absolute' and 'relative' used in reference to Soroka and Wlezien 2010). As the public adjusts its absolute preferences in a positive way to policy spending and legal policy provision changes, then by default their relative preferences adjust; and if relative public opinion has a moderate to large impact on policy then the public could drive its own absolute preferences to change, leading to the positive effect of policy on opinion observed in these results. Thus, the theories are compatible and the research reported in this paper does not argue in any way against the thermostatic perspective.

Given these data and models, a theory of positive returns in a system is simply the better explanation for what is taking place. The thermostatic model explains what takes place over shorter periods of time and helps keep a system on a path of longer-term positive returns. Therefore, both can be seen a theoretical processes that lead to positive feedback with differences in theoretical explanation bounded by length of timespans. However, neither theoretical perspective says anything about the direction that opinion and policy move, this can be increasing or declining returns. Given recent neoliberal policy agendas since the 1970s and 80s the expectation is that declining returns are underway. Thus, in order to extend Pierson's theoretical description of the golden age of welfare state growth to recent neoliberal turns, I adopted the label positive returns. More research should probe this theoretical extension and attempt to look outside the period investigated herein from 1985 through 2008, because it could represent a unique historical moment. Although Pierson's increasing returns work suggests that the process was in place throughout the history of welfare states, a simultaneous feedback model similar to the one employed here is difficult to test due to lack of historical public opinion data.

I propose a general theory of opinion-policy as a system where positive returns leads public opinion to partly be a product of policy shaping opinion over long periods of time and partly a product of opinion itself transmitted through policy thermostatically, the only requirement for this to be empirically feasible is that the impact of opinion on policy have a larger absolute value than policy on opinion. This is exactly what Wlezien and Soroka find and what I have found in the ideal Figure 5, and in various sensitivity tests ${ }^{11}$. These results apply to both spending and decommodification measures of policy and a general system theory of opinion-policy should grapple with various measures of policy as all types of policy could impact public opinion through social interaction, political rhetoric, media messages and the goods and services received (or not received) via the government; and all could have slightly different effects. Moreover, I have considered national government policy here, but more decentralized systems provide greater amounts of state and local-level social policy and this should be an area for future research. 
A side finding emerged in this undertaking. I did not focus on the effects of independent variables specifically, other than to make the model as close of an approximation of their theoretically causal relationships as possible. However, the consistently strong positive effect of GDP on both policy spending and decommodification supports something argued long ago by Wilensky (1975): that richer countries (i.e., more developed) spend more on social policy. However, this empirical phenomenon only appears to be true when comparing the poorer countries of the world to the richer countries. It does not appear to be true within the group of rich welfare states as borne out in much of the worlds of welfare literature, and the fact that for example Sweden and the U.S. have similar GDPs (correlation of GDP and social policy measures is near zero, see Table $4^{9}$ ). When modeling simultaneous feedback, I find a moderate positive effect of GDP on spending and decommodification in almost all the models, and this suggests that Wilensky's theory may still apply within rich democracies, but that the effect is suppressed in unidirectional models because of un-modeled, confounding endogeneity.

I considered large, rich democratic welfare state societies. However, the model could apply, if only to a lesser degree, to all societies. Without the consent of the governed or without successful coercion of the governed, the public are likely to revolt as suggest long ago by Machiavelli in Chapter 15 of The Prince. This threat of revolution may impact policy similar to democratic electoral processes, thus future research might look into more or less democratic states as well. Moreover, the results of models from these 19 democratic states are only a sliver of the full story of policy in each. There is no question that every policymaking and public opinion moment is produced by unique historical, socioeconomic, political, and other features in geographic space and time. This paper argues that there may be a common baseline relationship of opinion and policy that is ever-present, and which is complimented by the powerful forces peculiar to each context.

\subsection{Institutions and Equilibrium}

The relationships identified here - after correcting for endogeneity bias and applying instrumental variables - provide an empirical and theoretical starting point for further understanding and developing theories of the common causal linkages between opinion and policy. They suggest that an institutional positive returns perspective should be part of this development. This work provides theoretical and empirical evidence that equilibrium is part of the story of positive returns, or what is more generally known as institutional path dependency. There is an institutional component to the opinion-policy feedback relationship where the goods and services transferred by the government during the inception, or history of social policy become embedded norms on which individuals form their policy attitudes and expectations, and within which policymakers must operate. The norms are perpetuated through the social and political institutions of a given society. It is very costly for political actors to deviate from these norms because they define what range of actions are possible, and changing the norms would require overthrowing parts of the institutions - literally destroying legal and brick-and-mortar pieces of these institutions in many cases. These embedded institutions, and the expectations of policymakers and the public lead to an equilibrium between public opinion and social policy. Equilibrium is a product of normative institutions that exists despite shocks and cycles in 
the effects running between opinion and policy. The argument herein is that although punctuations likely exist in opinion-policy dynamics as discussed in the thermostatic perspective and punctuated equilibrium theories (Jones and Baumgartner 2012), they are so frequent and regularly occurring in stable democratic welfare states that they tend to smooth themselves out, leaving a core relationship of opinion and policy that is stable over time and across societies. Punctuations in the opinion-policy links are constantly starting, proceeding and coming to a close; therefore opinion and policy are at equilibrium within them - policy and opinion neither reach a stasis nor do they engender revolution.

Also, the looming question of what exactly is social policy challenges any theory to describe the relationship of public opinion and social policy. Policy spending may influence public opinion mostly through the media, whereas policy provisions of goods and services influence the public materially. Spending and the generosity of state-provided goods and services (i.e., decommodification) are highly correlated but retain distinct qualities. Although the positive returns model is always favored, ruling out the thermostatic model, or the freely estimated model which points toward positive returns, would be statistical overkill. Given a system at equilibrium, the effects between opinion and policy are the result of processes taking place across many years, cycles, budgets, elections, and other punctuations. The Wlezien and Soroka thermostatic model explicitly applies to a one year cycle. Therefore, seeing even slight evidence of it in a stable systems perspective spanning decades is unexpected, and suggests that policy could have a negative force acting on public opinion over long periods of time. A statistical explanation for what is discussed above is that there is a negative and positive coefficient of policy impacting opinion and that these represent distinct effects of policy; effects that alternative modeling and better measures would be needed to identity. This is evidenced by the ideal-type model in Figure 5, where opinion has a small effect on policy vis-à-vis a large effect of policy on opinion. Perhaps the small policy effect only appears small because there is a simultaneous negative effect suppressing it. Further research and theorizing should prove worthy in sorting out two types of simultaneous effects within the feedback loop, or one set of simultaneous effects and one set of cyclical effects.

\subsection{Methodological Discussion}

Theory is crucial to the methodological specification of a simultaneous feedback model. This requires at minimum a lay theory that opinion and policy are reciprocally related, yet models improve significantly when drawing on well-developed theories from Wlezien and Soroka, and Pierson, among others. Without imposing theoretical properties the simultaneous feedback model is un-identifiable statistically. Theory is required to derive the instrumental variables necessary for identification. As female labor force participation and veto points have some limitations, future research should search out other instruments. Also, without theory, the feedback effects of the freely estimated model are often not significant, sometimes seeminly implausible in size, and leave independent variables with also seemingly implausible effects. It is only after carefully applying opinion-policy theories that the models begins to function. Methods, at least in the case of a simultaneous feedback models, are a theoretical undertaking as much as a statistical one. This is a stark reminder that without theory a researcher could blindly arrive 
at any number of statistical models, many of which are meaningless, and thus draw uninformed and perhaps even theoretically impossible empirical conclusions.

Another methodological issue stems from the measurement of public opinion. The ISSP data has at least 2items by which to measure public opinion. Here I averaged them to create the dependent variable. However, a measurement model would be preferable as public opinion toward social policy in general (i.e., the entire welfare state system) is something latent, not observed in individual questions on specific policies. But this is not possible given the limited degrees of freedom. Sensitivity tests in Table $5^{9}$ model a one-minus the opinion alpha reliability to try and account for the known measurement error in the scale, results are similar but the models are clumsy. To assign a specific measurement error in the model forces ignorance of other potential sources of error and may falsely achieve identification or fit, and thus may be a risky methodological choice without a strong argument why the error path is exactly a given value ${ }^{12}$.

The simultaneous feedback model is especially designed to estimate reciprocal (total) causality in crosssectional data. This is a blessing and a burden. It is a tool to unlock the limitations of sporadically fielded crossnational surveys in both timing and country-coverage. However, it would be plausible to adapt the feedback model to longitudinal data looking at each year as a case and attempting to determine if the general opinion-policy relationship, i.e., equilibrium, is present over many decades. The trick here would be to find instrumental variables, as female labor force participation and veto points are only suited to be cross-national instruments. If scholars manage to construct within-country feedback models, their results might be compared to those of Soroka and Wlezien and to the vector auto-regression studies that find that the effects of opinion and policy on each other change over the years before and after a policy moment. Given the theoretical argument here, I would expect that across the variation in effect sizes by year, there would be a common core effect. This would be a fruitful application of the simultaneous feedback theory where there are $\beta_{1}$ and $\beta_{2}$ which have constant feedback effects each year (fixed-coefficients), and then $\beta_{1 i}$ and $\beta_{2 i}$ that have varying effects by year (random-coefficients). At this stage, researchers have not identified within-country instruments, thus the longitudinal simultaneous feedback model remains purely theoretical.

The partisan component of these models calls for further research. The partisan make-up of government threatens arguments of equilibrium. There are constant efforts by parties to make policy; however, their capacities to influence policy (and perhaps public opinion) are greatly enhanced based on the number of seats they hold. The distribution of seats is erratic over time. It is a product of public opinion, media and how well policy serves public interests. Therefore partisan control is also endogenous with public opinion and social policy and a theoretical model should have reciprocal causality running between opinion, policy and partisan control of government. As modeling more endogenous dependent variables is beyond the scope of this paper and the data, I settled for right party control as an independent variable, despite knowing that opinion and policy both influence it as well. However, I ran sensitivity models omitting right party seats as a variable, with the assumption that the reciprocal impact goes in to the total effects running between opinion and policy and the error covariance. When doing this all models tend to fit

\footnotetext{
${ }^{12}$ I conclude this based on expert discussions on the SEMNET listserve.
} 
well (see Models $10 \mathrm{Ar}-12 \mathrm{Dr}^{9}$ ) pointing toward the strained role of right party seats as a variable in a simultaneous feedback model, but given its prominent theoretical role in opinion and policy I keep it in the main models. Also, the sensitivity results still largely favor the positive returns model, and in the case of the freely estimated Model $10 \mathrm{Cr}$, results point toward the modified positive returns model (Figure 5) where policy has a larger impact on opinion than opinion on policy; i.e., $\beta_{1}$ larger than $\beta_{2}$. 


\section{BIBLIOGRAPHY}

Allison, Paul D. 1990. "Change Scores as Dependent Variables in Regression Analysis." Sociological Methodology 20:93-114.

Anderies, John M, and Marco A Janssen. 2013. "Robustness of Social-Ecological Systems: Implications for Public Policy." Policy Studies Journal 41(3):513-36.

Andreß, Hans-Jürgen, and Thorsten Heien. 2001. "Four Worlds of Welfare State Attitudes? A Comparison of Germany, Norway and the United States." European Sociological Review 17(4):337-56.

Bartels, Larry M. 1986. "Issue Voting Under Uncertainty: An Empirical Test.” American Journal of Political Science 30(4):709-28.

Bean, Clive, and Elim Papadakis. 1998. "A Comparison of Mass Attitudes towards the Welfare State in Different Institutional Regimes, 1985-1990.” International Journal of Public Opinion Research 10(3):211-36.

Bendz, Anna. 2015. "Paying Attention to Politics: Public Responsiveness and Welfare Policy Change." Policy Studies Journal 43(3):309-32.

Blekesaune, Morten. 2007. "Economic Conditions and Public Attitudes to Welfare Policies." European Sociological Review 23(3):393-403.

Blekesaune, Morten, and Jill Quadagno. 2003. "Public Attitudes toward Welfare State Policies: A Comparative Analysis of 24 Nations." European Sociological Review 19(5):415-27.

Bollen, Kenneth A. 1989. Structural Equations with Latent Variables. New York, NY: Wiley.

. 2012. "Instrumental Variables in Sociology and the Social Sciences." Annual Review of Sociology $38(1): 37-72$.

Bollen, Kenneth A, Barbara Entwisle, and Arthur S Alderson. 1993. "Macrocomparative Research Methods." Annual Review of Sociology 19:321-51.

Breznau, Nate. 2010. "Economic Equality and Social Welfare: Policy Preferences in Five Nations." International Journal of Public Opinion Research 22(4):458-84.

2015. "The Missing Main Effect of Welfare State Regimes: A Replication of 'Social Policy Responsiveness in Developed Democracies’ by Brooks and Manza.” Sociological Science 2:420-41.

Breznau, Nate, and Maureen A Eger. 2016 (forthcoming). "Immigrant Presence, Group Boundaries, and Support for the Welfare State in Western European Societies." Acta Sociologica.

Brooks, Clem, and Jeff Manza. 2007. Why Welfare States Persist: The Importance of Public Opinion in Democracies. Chicago: University of Chicago Press.

Butler, Daniel M, and David W Nickerson. 2011. "Can Learning Constituency Opinion Affect How Legislators Vote? Results from a Field Experiment.” Quarterly Journal of Political Science 6(1): 55-83.

Campbell, Andrea Louise. 2012. "Policy Makes Mass Politics." Annual Review of Political Science 15(1):333-51.

Castles, Francis G. 2009. "What Welfare States Do: A Disaggregated Expenditure Approach.” Journal of Social Policy 38(1):45-62.

Converse, Philip E. 1987. "Changing Conceptions of Public Opinion in the Political Process." The Public Opinion Quarterly 51:S12-24.

Crepaz, Markus M L, and Ann W Moser. 2004. "The Impact of Collective and Competitive Veto Points on Public Expenditures in the Global Age.” Comparative Political Studies 37(3):259-85.

Däubler, Thomas. 2008. "Veto Players and Welfare State Change: What Delays Social Entitlement Bills?” Journal 
of Social Policy 37(4):683-706.

DiMaggio, Paul J, and Walter W Powell. 1983. "The Iron Cage Revisited: Institutional Isomorphism and Collective Rationality in Organizational Fields." American Sociological Review 48(2):147-60.

Downs, Anthony. 1957. An Economic Theory of Democracy. New York: Harper and Row.

Duncan, O D, A O Haller, and A Portes. 1968. "Peer Influences on Aspirations: A Reinterpretation." American Journal of Sociology 74(2):119-37.

Durkheim, Emile. 1964. The Division of Labor in Society. ed. George (Translator) Simpson. New York: Free Press.

Durr, Robert H. 1993. “What Moves Policy Sentiment?.” American Political Science Review 87(1):158-70.

Easton, David. 1965. A Framework for Political Analysis. Englewood Cliffs, New Jersey: Prentice-Hall.

Ebbinghaus, Bernhard. 2005a. "Can Path Dependence Explain Institutional Change? Two Approaches Applied to Welfare State Reform." Max Plank Institute for the Study of Societies MPlfG Disc(05/2).

_. 2005b. "When Less Is More: Selection Problems in Large-N and Small-N Cross-National Comparisons." International Sociology 20(2): 133-52.

Eger, Maureen A. 2010. "Even in Sweden: The Effect of Immigration on Support for Welfare State Spending." European Sociological Review 26(2):203-17.

Esping-Andersen, Gøsta. 1985. "Power and Distributional Regimes.” Politics \& Society 14(2):223-56. 1990. The Three Worlds of Welfare Capitalism. Oxford: Oxford University Press.

Evans, M D R, Jonathan Kelley, and Clayton D Peoples. 2010. "Justifications of Inequality: The Normative Basis of Pay Differentials in 31 Nations." Social Science Quarterly 91(5):1405-31.

Freeman, John R, John T Williams, and Tse-min Lin. 1989. "Vector Autoregression and the Study of Politics." American Journal of Political Science 33(4):842-77.

Gabel, Matthew, and Kenneth Scheve. 2007. "Estimating the Effect of Elite Communications on Public Opinion Using Instrumental Variables." American Journal of Political Science 51(4):1013-28.

Gelissen, John. 2000. "Popular Support for Institutionalised Solidarity: A Comparison between European Welfare States." International Journal of Social Welfare 9:285-300.

Gërxhani, Klarita, and Ferry Koster. 2012. “'I Am Not Alone’: Understanding Public Support for the Welfare State." International Sociology 27(6 ):768-87.

Green-Pedersen, Christoffer. 2004. "The Dependent Variable Problem within the Study of Welfare State Retrenchment: Defining the Problem and Looking for Solutions." Journal of Comparative Policy Analysis: Research and Practice 6(1):3-14.

Habel, Philip D. 2012. "Following the Opinion Leaders? The Dynamics of Influence Among Media Opinion, the Public, and Politicians." Political Communication 29(3):257-77.

Habermas, Jürgen. 1989. The Structural Transformation of the Public Sphere: An Inquiry into a Category of Bourgeois Society. English Tr. eds. Thomas Burger and Frederick Lawrence. Cambridge, MA: MIT Press.

Hacker, Jacob S. 2004. "Privatizing Risk without Privatizing the Welfare State: The Hidden Politics of Social Policy Retrenchment in the United States." American Political Science Review 98(2):243-60.

Hakhverdian, Armen. 2012. "The Causal Flow between Public Opinion and Policy: Government Responsiveness, Leadership, or Counter Movement?" West European Politics 35(6):1386-1406.

Hall, Peter A, and Michèle Lamont. 2013. "Why Social Relations Matter for Politics and Successful Societies." Annual Review of Political Science 16(1):49-71. 
Hall, Peter A, and Rosemary C R Taylor. 1996. "Political Science and the Three New Institutionalisms." Political Studies 44(5):936-57.

Hasenfeld, Yeheskel, and Jane A Rafferty. 1989. "The Determinants of Public Attitudes toward the Welfare State." Social Forces 67(4):1027-48.

Hill, Kim Quaile, and Angela Hinton-Andersson. 1995. "Pathways of Representation: A Causal Analysis of Public Opinion-Policy Linkages.” American Journal of Political Science 39(4):924-35.

Homans, George C. 1974. Social Behavior: Its Elementary Forms. New York: Harcourt, Brace, Jovanovich.

Huber, Evelyne, Charles Ragin, and John D Stephens. 1993. "Social Democracy, Christian Democracy, Constitutional Structure, and the Welfare State." The American Journal of Sociology 99(3):711-49.

Huber, Evelyne, and John D Stephens. 2000. "Partisan Governance, Women's Employment, and the Social Democratic Service State." American Sociological Review 65(3):323-42.

Jæger, Mads Meier. 2006. "What Makes People Support Public Responsibility for Welfare Provision: Self-Interest or Political Ideology? A Longitudinal Approach.” Acta Sociologica 49(3):321-38.

Jennings, Will. 2009. "The Public Thermostat, Political Responsiveness and Error-Correction: Border Control and Asylum in Britain, 1994-2007.” British Journal of Political Science 39(4):847-70.

Jensen, Carsten. 2011. "Two Sides of the Same Coin? Left-Wing Governments and Labour Unions as Determinants of Public Spending." Socio-Economic Review 10(2):217-240.

Jepperson, Ronald. 1991. "Institutions, Institutional Effects, and Institutionalism." In The New Institutionalism in Organizational Analysis, eds. Walter W Powell and Paul J DiMaggio. Chicago: University of Chicago Press, 143-63.

Jones, Bryan D, and Frank R Baumgartner. 2004. “Representation and Agenda Setting.” Policy Studies Journal 32(1):1-24. - 2012. "From There to Here: Punctuated Equilibrium to the General Punctuation Thesis to a Theory of Government Information Processing." Policy Studies Journal 40(1):1-20.

Kenworthy, Lane. 1999. "Do Social-Welfare Policies Reduce Poverty? A Cross-National Assessment.” Social Forces 77(3): 1119-39.

Kline, Rex B. 2011. Principles and Practice of Structural Equation Modeling. Third. New York, NY: Guilford Press.

. 2013. "Reverse Arrow Dynamics: Feedback Loops and Formative Measurement." In Structural Equation Modeling: A Second Course, eds. Gregory R. Hancock and Ralph O. Mueller. Charlotte, NC: Information Age Publishing,41-79.

Knight, Carly R., and Christopher Winship. 2013. "The Causal Implications of Mechanistic Thinking: Identification Using Directed Acyclic Graphs (DAGs)." In Handbook of Causal Analysis for Social Research, Handbooks of Sociology and Social Research, ed. Stephen L Morgan. Springer Netherlands,275-99.

Korpi, Walter, and Joakim Palme. 2003. "New Politics and Class Politics in the Context of Austerity and Globalization: Welfare State Regress in 18 Countries." American Political Science Review 97(3): 425-46.

Larsen, Christian Albrekt. 2008. "The Institutional Logic of Welfare Attitudes: How Welfare Regimes Influence Public Support." Comparative Political Studies 41(2):145-68.

Lee, Han Soo. 2014. "Analyzing the Multidirectional Relationships Between the President, News Media, and the Public: Who Affects Whom?" Political Communication 31(2):259-81.

Lidtke, Vernon L. 1966. The Outlawed Party: Social Democracy in Germany 1878-1890. English Tr. Princeton, NJ:Princeton University Press. 
Lijphart, Arend. 1999. Patterns of Democracy: Government Forms and Performance in Thirty-Six Countries. New Haven and London:Yale University Press.

Lipset, Seymour Martin. 1960. Political Man: The Social Bases of Politics. Garden City, NY:Doubleday and Company.

Luhmann, Niklas. 1982. "The World Society as a Social System.” International Journal of General Systems $8(3): 131-38$.

Matsusaka, John G. 2005. “The Endogeneity of the Initiative: A Comment on Marschall and Ruhil." State Politics \& Policy Quarterly 5(4):356-63.

Meltzer, Allan H, and Scott F Richard. 1981. "A Rational Theory of the Size of Government." The Journal of Political Economy 89(5):914-27.

Mettler, Suzanne, and Joe Soss. 2004. "The Consequences of Public Policy for Democratic Citizenship: Bridging Policy Studies and Mass Politics." Perspectives on Politics 2(1):55-73.

Meyer, John W, and Brian Rowan. 1977. "Institutionalized Organizations: Formal Structure as Myth and Ceremony.” American Journal of Sociology 83(2):340-63.

Miller, Wakken E, and Donald E Stokes. 1963. "Constituency Influence in Congress." American Political Science Review 57(1):45-56.

Morgan, Kimberly J, and Andrea Louise Campbell. 2011. 1 The Delegated Welfare State: Medicare, Markets, and the Governance of Social Policy. New York:Oxford University Press USA.

Mullinix, Kevin J. 2011. "Lingering Debates and Innovative Advances: The State of Public Opinion Research." Policy Studies Journal 39(s1):61-76.

North, Douglass C. 1990. Institutions, Institutional Change and Economic Performance. Cambridge: Cambridge University Press.

Nowlin, Matthew C. 2011. "Theories of the Policy Process: State of the Research and Emerging Trends." Policy Studies Journal 39(s1):41-60.

OECD. 2012. Social Expenditures Database. www.oecd.org, accessed 01.10.2012:Organization for Economic Cooperation and Development.

Ostrom, Elinor. 2011. "Background on the Institutional Analysis and Development Framework." Policy Studies Journal 39(1):7-27.

Page, Benjamin I, and Robert Y Shapiro. 1983. "Effects of Public Opinion on Policy." The American Political Science Review 77(1):175-190

Pampel, Fred C, and John B Williamson. 1988. "Welfare Spending in Advanced Industrial Democracies, 19501980.” American Journal of Sociology 93(6):1424-56.

Papadakis, Elim. 1992. "Public Opinion, Public Policy and the Welfare State." Political Studies 40(1):21-37.

Paxton, Pamela, John R. Hipp, and Sandra Marquat-Pyatt. 2011. Nonrecursive Models: Endogeneity, Reciprocal Relationships and Feedback Loops. London: Sage Publications, Ltd.

Pearl, Judea. 2009. Causality: Models, Reasoning and Inference. 2nd ed. New York, NY, USA: Cambridge University Press.

Pedhazur, Elazar J. 1997. Multiple Regression in Behavioral Research: Explanation and Prediction. New York: Thomson Learning.

Pierson, Paul. 1993. "When Effect Becomes Cause: Policy Feedback and Political Change." World Politics 45(4):595-628. 
1994. Dismantling the Welfare State? Reagan, Thatcher and the Politics of Retrenchment. Cambridge: Cambridge Univ Press.

1996. “The New Politics of the Welfare State." World Politics 48(2):143-79.

1998. "Irresistible Forces, Immovable Objects: Post-Industrial Welfare States Confront Permanent Austerity." Journal of European Public Policy 5(4):539-60.

- 2000. "Increasing Returns, Path Dependence, and the Study of Politics." The American Political Science Review 94(2):251-67.

2002. "Coping with Permanent Austerity: Welfare State Restructuring in Affluent Democracies." Revue française de sociologie 43(2):369-406.

Poterba, James M. 1995. "Capital Budgets, Borrowing Rules, and State Capital Spending." Journal of Public Economics 56(2):165-87.

Raven, Judith, Peter Achterberg, Romke van der Veen, and Mara Yerkes. 2011. "An Institutional Embeddedness of Welfare Opinions? The Link Between Public Opinion and Social Policy in the Netherlands (1970-2004)." Journal of Social Policy 40(2):369-86.

Roosma, Femke, Wim van Oorschot, and John Gelissen. 2014. "The Preferred Role and Perceived Performance of the Welfare State: European Welfare Attitudes from a Multidimensional Perspective." Social Science Research 44C:200-210.

Schumacher, Gijs, Barbara Vis, and Kees van Kersbergen. 2013. "Political Parties' Welfare Image, Electoral Punishment and Welfare State Retrenchment." Comparative European Politics 11(1):1-21.

Scruggs, Lyle. 2004. Welfare State Entitlements Data Set: A Comparative Institutional Analysis of Eighteen Welfare States. Version 1.2: http://sp.uconn.edu/ scruggs/\#cwed.

Skocpol, Theda. 1988. "The Limits of the New Deal System and the Roots of Contemporary Welfare Dilemmas." In The Politics of Social Policy in the United States, eds. Margaret Weir, Ann Shola Orloff, and Theda Skocpol. Princenton: Princeton University Press,293-311.

1992. Protecting Soldiers and Mothers: The Political Origins of Social Policy in the United States. Cambridge, MA: Belknap Press.

Soroka, Stuart N, and Christopher Wlezien. 2010. Degrees of Democracy: Politics, Public Opinion and Policy. Cambridge: Cambridge University Press.

Soss, Joe, and Sanford F Schram. 2007. “A Public Transformed? Welfare Reform as Policy Feedback.” The American Political Science Review 101(1):111-27.

Starke, Peter. 2006. "The Politics of Welfare State Retrenchment: A Literature Review.” Social Policy \& Administration 40(1):104-20.

Steele, Liza G. 2015. "Income Inequality, Equal Opportunity, and Attitudes About Redistribution." Social Science Quarterly 96(2):444-64.

Stimson, James A, Michael B Mackuen, and Robert S Erikson. 1995. "Dynamic Representation." The American Political Science Review 89(3):543-65.

Svallfors, Stefan. 1997. "Worlds of Welfare and Attitudes to Redistribution: A Comparison of Eight Western Nations." European Sociological Review 13(3):283-304.

Taylor-Gooby, Peter. 2001. “Sustaining State Welfare in Hard Times: Who Will Foot the Bill?" Journal of European Social Policy 11(2):133-47.

Tepe, Markus, and Pieter Vanhuysse. 2010. "Elderly Bias, New Social Risks and Social Spending: Change and Timing in Eight Programmes across Four Worlds of Welfare, 1980-2003." Journal of European Social Policy 
$20(3): 217-34$.

Thelen, Kathleen. 1999. "Historical Institutionalism in Comparative Politics." Annu. Rev. Polit. Sci. 2(1):369-404. - 2014. Varieties of Liberalization and the New Politics of Social Solidarity. Cambridge: Cambridge University Press.

Vowles, Jack. 1995. “The Politics of Electoral Reform in New Zealand.” International Political Science Review 16(1):95-115.

Weber, Max. 1946. From Max Weber : Essays in Sociology. eds. Hans Heinrich Gerth and C. Wright Mills. New York: Oxford University Press.

Weir, Margaret, and Theda Skocpol. 1985. "State Structures and the Possibilities for 'Keynesian' Responses to the Great Depression in Sweden, Britain, and the United States." In Bringing the State Back In, eds. Peter B Evans, Dietrich Rueschemeyer, and Theda Skocpol. Cambridge: Cambridge University Press,107-63.

Wilensky, Harold L. 1975. The Welfare State and Equality: Structural and Ideological Roots of Public Expenditure. Berkeley: University of California Press.

Wlezien, Christopher. 1995. "The Public as Thermostat: Dynamics of Preferences for Spending." American Journal of Political Science 39(4):981-1000.

Wlezien, Christopher, and Stuart Soroka. 2007. "Relationships between Public Opinion and Policy." In Oxford Handbook of Political Behavior, eds. Russell Dalton and Hans-Deiter Klingemann. Oxford: Oxford University Press,799-817.

Wlezien, Christopher, and Stuart N Soroka. 2012. "Political Institutions and the Opinion-Policy Link." West European Politics 35(6):1407-32.

Wright, Sewall. 1934. "The Method of Path Coefficients." The Annals of Mathematical Statistics 5(3):161-215. 